Bond University

Research Repository

\title{
Systemic corticosteroids for acute sinusitis
}

Venekamp, Roderick P.; Thompson, Matthew J.; Hayward, Gail; Heneghan, Carl J.; Del Mar, Chris B.; Perera, Rafael; Glasziou, Paul P.; Rovers, Maroeska M.

Published in:

Cochrane Database of Systematic Reviews

DOI:

10.1002/14651858.CD008115.pub3

Licence:

Other

Link to output in Bond University research repository.

Recommended citation(APA):

Venekamp, R. P., Thompson, M. J., Hayward, G., Heneghan, C. J., Del Mar, C. B., Perera, R., Glasziou, P. P., \& Rovers, M. M. (2014). Systemic corticosteroids for acute sinusitis. Cochrane Database of Systematic Reviews, 2014(3), [CD008115]. https://doi.org/10.1002/14651858.CD008115.pub3

\section{General rights}

Copyright and moral rights for the publications made accessible in the public portal are retained by the authors and/or other copyright owners and it is a condition of accessing publications that users recognise and abide by the legal requirements associated with these rights.

For more information, or if you believe that this document breaches copyright, please contact the Bond University research repository coordinator. 


\section{(E) Cochrane Library}

Cochrane Database of Systematic Reviews

\section{Systemic corticosteroids for acute sinusitis (Review)}

Venekamp RP, Thompson MJ, Hayward G, Heneghan CJ, Del Mar CB, Perera R, Glasziou PP, Rovers MM

Venekamp RP, Thompson MJ, Hayward G, Heneghan CJ, Del Mar CB, Perera R, Glasziou PP, Rovers MM.

Systemic corticosteroids for acute sinusitis.

Cochrane Database of Systematic Reviews 2014, Issue 3. Art. No.: CD008115.

DOI: 10.1002/14651858.CD008115.pub3.

www.cochranelibrary.com 
HEADER

ABSTRACT

PLAIN LANGUAGE SUMMARY

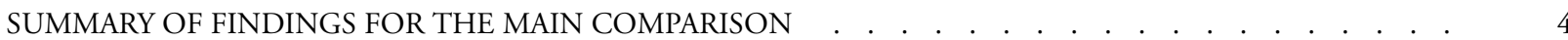

BACKGROUND . . . . . . . . . . . . . . . . . . . . . . . . . . . . . . . . . . . . . . 7

OBJECTIVES . . . . . . . . . . . . . . . . . . . . . . . . . . . . . . . . . . . . . . . . . . . .

METHODS . . . . . . . . . . . . . . . . . . . . . . . . . . . . . . . . . . . . . . . . 8

Figure 1. . . . . . . . . . . . . . . . . . . . . . . . . . . . . . . . . . . . . . 10

Figure 2. . . . . . . . . . . . . . . . . . . . . . . . . . . . . . . . . . . . . .

RESULTS . . . . . . . . . . . . . . . . . . . . . . . . . . . . . . . . . . . . . . . . . . .

Figure 3. . . . . . . . . . . . . . . . . . . . . . . . . . . . . . . . . . . . . . 14

Figure 4. . . . . . . . . . . . . . . . . . . . . . . . . . . . . . . . . . . . . . . .

Figure 5. . . . . . . . . . . . . . . . . . . . . . . . . . . . . . . . . . . . . . 15

Figure 6. . . . . . . . . . . . . . . . . . . . . . . . . . . . . . . . . . . . . . 16

DISCUSSION . . . . . . . . . . . . . . . . . . . . . . . . . . . . . . . . . . . . . . . . . 16

AUTHORS' CONCLUSIONS . . . . . . . . . . . . . . . . . . . . . . . . . . . . . . . . . . . . . .

ACKNOWLEDGEMENTS . . . . . . . . . . . . . . . . . . . . . . . . . . . . . . . . . . . . . . 18

REFERENCES . . . . . . . . . . . . . . . . . . . . . . . . . . . . . . . . . . . . . . . . . . . . . 19

CHARACTERISTICS OF STUDIES . . . . . . . . . . . . . . . . . . . . . . . . . . . . . . . . . . . . . . . . . .

DATA AND ANALYSES . . . . . . . . . . . . . . . . . . . . . . . . . . . . . . . . . . . . . . . . . . . . . . . . . . . . .

Analysis 1.1. Comparison 1 Oral corticosteroids versus placebo or NSAID, Outcome 1 Proportion of patients with resolution or improved symptoms at days 3 to $7 . \quad$. . . . . . . . . . . . . . . . . . . . . . . . . . . . . . .

Analysis 1.2. Comparison 1 Oral corticosteroids versus placebo or NSAID, Outcome 2 Proportion of patients with resolution or improved symptoms at days 4 to 14 .

Analysis 2.1. Comparison 2 Sensitivity analysis - oral corticosteroids versus placebo, Outcome 1 Proportion of patients with resolution or improved symptoms at days 3 to 7.

Analysis 2.2. Comparison 2 Sensitivity analysis - oral corticosteroids versus placebo, Outcome 2 Proportion of patients with resolution or improved symptoms at days 4 to 14 .

Analysis 3.1. Comparison 3 Best and worst-case scenario - oral corticosteroids versus NSAID or placebo, Outcome 1 Proportion of patients with resolution or improved symptoms at days 3 to 7 - best-case scenario.

Analysis 3.2. Comparison 3 Best and worst-case scenario - oral corticosteroids versus NSAID or placebo, Outcome 2 Proportion of patients with resolution or improved symptoms at days 3 to 7 - worst-case scenario.

Analysis 3.3. Comparison 3 Best and worst-case scenario - oral corticosteroids versus NSAID or placebo, Outcome 3 Proportion of patients with resolution or improved symptoms at days 4 to 14 - best-case scenario. . . . . .

Analysis 3.4. Comparison 3 Best and worst-case scenario - oral corticosteroids versus NSAID or placebo, Outcome 4 Proportion of patients with resolution or improved symptoms at days 4 to 14 - worst-case scenario.

Analysis 4.1. Comparison 4 Best and worst-case scenario - oral corticosteroids versus placebo, Outcome 1 Proportion of patients with resolution or improved symptoms at days 3 to 7 - best-case scenario.

Analysis 4.2. Comparison 4 Best and worst-case scenario - oral corticosteroids versus placebo, Outcome 2 Proportion of patients with resolution or improved symptoms at days 3 to 7 - worst-case scenario. . . . . . . . . . .

Analysis 4.3. Comparison 4 Best and worst-case scenario - oral corticosteroids versus placebo, Outcome 3 Proportion of patients with resolution or improved symptoms at days 4 to 14 - best-case scenario. . . . . . . . . . . . .

Analysis 4.4. Comparison 4 Best and worst-case scenario - oral corticosteroids versus placebo, Outcome 4 Proportion of patients with resolution or improved symptoms at days 4 to 14 - worst-case scenario.

ADDITIONAL TABLES .

APPENDICES

WHAT'S NEW

CONTRIBUTIONS OF AUTHORS

DECLARATIONS OF INTEREST

SOURCES OF SUPPORT

INDEX TERMS

Systemic corticosteroids for acute sinusitis (Review)

Copyright (? 2014 The Cochrane Collaboration. Published by John Wiley \& Sons, Ltd. 


\title{
[Intervention Review]
}

\section{Systemic corticosteroids for acute sinusitis}

\author{
Roderick P Venekamp ${ }^{1}$, Matthew J Thompson ${ }^{2}$, Gail Hayward ${ }^{3}$, Carl J Heneghan ${ }^{3}$, Chris B Del Mar ${ }^{4}$, Rafael Perera ${ }^{3}$, Paul P Glasziou \\ ${ }^{4}$, Maroeska M Rovers ${ }^{5}$ \\ ${ }^{1}$ Department of Otorhinolaryngology \& Julius Center for Health Sciences and Primary Care, University Medical Center Utrecht, \\ Utrecht, Netherlands. ${ }^{2}$ Department of Family Medicine, University of Washington, Seattle, WA, USA. ${ }^{3}$ Nuffield Department of \\ Primary Care Health Sciences, University of Oxford, Oxford, UK. ${ }^{4}$ Centre for Research in Evidence-Based Practice (CREBP), Bond \\ University, Gold Coast, Australia. ${ }^{5}$ Department of Operating Rooms, Radboud University Nijmegen Medical Centre, Nijmegen, \\ Netherlands
}

Contact address: Matthew J Thompson, Department of Family Medicine, University of Washington, Box 354696, Seattle, WA, $98195-$ 4696, USA. matthew.thompson61@gmail.com, matthew.thompson@phc.ox.ac.uk.

Editorial group: Cochrane Acute Respiratory Infections Group.

Publication status and date: New search for studies and content updated (no change to conclusions), published in Issue 3, 2014

Citation: Venekamp RP, Thompson MJ, Hayward G, Heneghan CJ, Del Mar CB, Perera R, Glasziou PP, Rovers MM. Systemic corticosteroids for acute sinusitis. Cochrane Database of Systematic Reviews 2014, Issue 3. Art. No.: CD008115. DOI: 10.1002/14651858.CD008115.pub3.

Copyright (C) 2014 The Cochrane Collaboration. Published by John Wiley \& Sons, Ltd.

\section{A B S T R A C T}

\section{Background}

Acute sinusitis is the inflammation and swelling of the nasal and paranasal mucous membranes and is a common reason for patients to seek primary care consultations. The related impairment of daily functioning and quality of life is attributable to symptoms such as facial pain and nasal congestion.

\section{Objectives}

To assess the effects of systemic corticosteroids on clinical response rates and to determine adverse effects and relapse rates of systemic corticosteroids compared to placebo or standard clinical care in children and adults with acute sinusitis.

\section{Search methods}

We searched CENTRAL (2014, Issue 1), MEDLINE (1966 to February week 1, 2014) and EMBASE (January 2009 to February 2014).

\section{Selection criteria}

Randomised controlled trials (RCTs) comparing systemic corticosteroids to placebo or standard clinical care for patients with acute sinusitis.

\section{Data collection and analysis}

Two review authors independently assessed the methodological quality of the trials and extracted data.

\section{Main results}

Five RCTs with a total of 1193 adult participants met our inclusion criteria. We judged methodological quality to be moderate in four trials and high in one trial. Acute sinusitis was defined clinically in all trials. However, the three trials performed in ear, nose and throat (ENT) outpatient clinics also used radiological assessment as part of their inclusion criteria. All participants were assigned to either oral corticosteroids (prednisone $24 \mathrm{mg}$ to $80 \mathrm{mg}$ daily or betamethasone $1 \mathrm{mg}$ daily) or the control treatment (placebo in four 
trials and non-steroidal anti-inflammatory drugs (NSAIDs) in one trial). In four trials antibiotics were prescribed in addition to oral corticosteroids or control treatment, while one trial investigated the effects of oral corticosteroids as a monotherapy.

When combining data from the five trials, participants treated with oral corticosteroids were more likely to have short-term resolution or improvement of symptoms than those receiving the control treatment: at days three to seven (risk ratio (RR) 1.3 , 95\% confidence interval (CI) 1.1 to 1.6; risk difference (RD) $17 \%$, 95\% CI 6\% to 29\%) and at days four to 14 (RR 1.2, $95 \%$ CI 1.0 to 1.5 ; RD $14 \%, 95 \%$ CI $1 \%$ to $27 \%$ ). A sensitivity analysis including the four trials with placebo as a control treatment showed similar results but with a lesser effect size: at days three to seven (RR 1.2, 95\% CI 1.1 to 1.3 ; RD $11 \%, 95 \%$ CI $4 \%$ to $17 \%$ ) and days four to 14 (RR 1.1, 95\% CI 1.0 to 1.2 ; RD 8\%, 95\% CI 2\% to 13\%). Statistical heterogeneity was high for many analyses. Subgroup analyses revealed that corticosteroid monotherapy had no beneficial effects. Furthermore, scenario analysis showed that outcomes missing from the trial reports might have introduced attrition bias (a worst-case scenario showed no statistically significant beneficial effect of oral corticosteroids). No trial reported effects on relapse or recurrence rates. Reported side effects in patients treated with oral corticosteroids were mild (nausea, vomiting, gastric complaints) and did not significantly differ from those receiving placebo.

\section{Authors' conclusions}

Oral corticosteroids as a monotherapy appear to be ineffective for adult patients with clinically diagnosed acute sinusitis. Current data on the use of oral corticosteroids as an adjunctive therapy to oral antibiotics are limited: almost all trials are performed in secondary care settings and there is a significant risk of bias. This limited evidence suggests that oral corticosteroids in combination with antibiotics may be modestly beneficial for short-term relief of symptoms in acute sinusitis, with a number needed to treat to benefit of seven for resolution or symptom improvement. A large primary care factorial trial is needed to establish whether oral corticosteroids offer additional benefits over antibiotics in acute sinusitis.

\section{PLAIN LANGUAGE SUMMARY}

\section{Steroidal anti-inflammatory medication given by mouth or injection for acute sinusitis}

\section{Review question}

We reviewed the evidence about the effect of steroidal anti-inflammatory medication (i.e. corticosteroids) given by mouth or injection (i.e. systemically) compared to placebo or standard clinical care on acute attacks of nose and sinus complaints (i.e. acute sinusitis) in children and adults.

\section{Background}

Acute sinusitis may be caused directly by viral or bacterial infections and by the body's inflammatory response to these infections. Therefore, anti-inflammatory treatments may be effective in treating this condition. Earlier reviews found only modest beneficial effects of corticosteroids given by nasal spray. It is unclear if this is because the intranasal corticosteroids did not actually reach the (blocked) nasal passages or because anti-inflammatory drugs do not work.

\section{Study characteristics}

This review included evidence up to 19 February 2014. Five trials involving 1193 participants aged 15 years and older with acute sinusitis were included. In four trials participants received either antibiotics plus oral corticosteroids or antibiotics plus control treatment, while one trial assessed the effects of corticosteroids alone. Information on symptom relief was only available for the short term (two weeks or less) and no trial reported on relapse rates. No data for children were available.

\section{Key outcomes}

After combining trial findings, the results suggest that adults treated with oral corticosteroids plus antibiotics are more likely to have short-term symptom relief than those receiving a placebo or non-steroidal anti-inflammatory drug plus antibiotics. To benefit a single person, seven would need to receive treatment (number needed to treat to benefit). The trial assessing the effects of oral corticosteroids without antibiotics found no beneficial effects compared to placebo. Reported side effects in patients treated with oral corticosteroids were mild (nausea, vomiting, gastric complaints) and did not significantly differ from those receiving placebo.

\section{Quality of the evidence}

We judged the quality of the evidence for oral corticosteroids plus antibiotics to be low (further research is very likely to have an important impact on our confidence in the effect estimate and is likely to change the estimate) as the evidence is derived from four 
trials, including a relatively low number of participants, with a substantial risk of bias. Evidence of the effect of oral corticosteroids without antibiotics is derived from only one high-quality trial and we therefore judged the quality to be moderate (further research is likely to have an important impact on our confidence in the effect estimate and may change the estimate). 


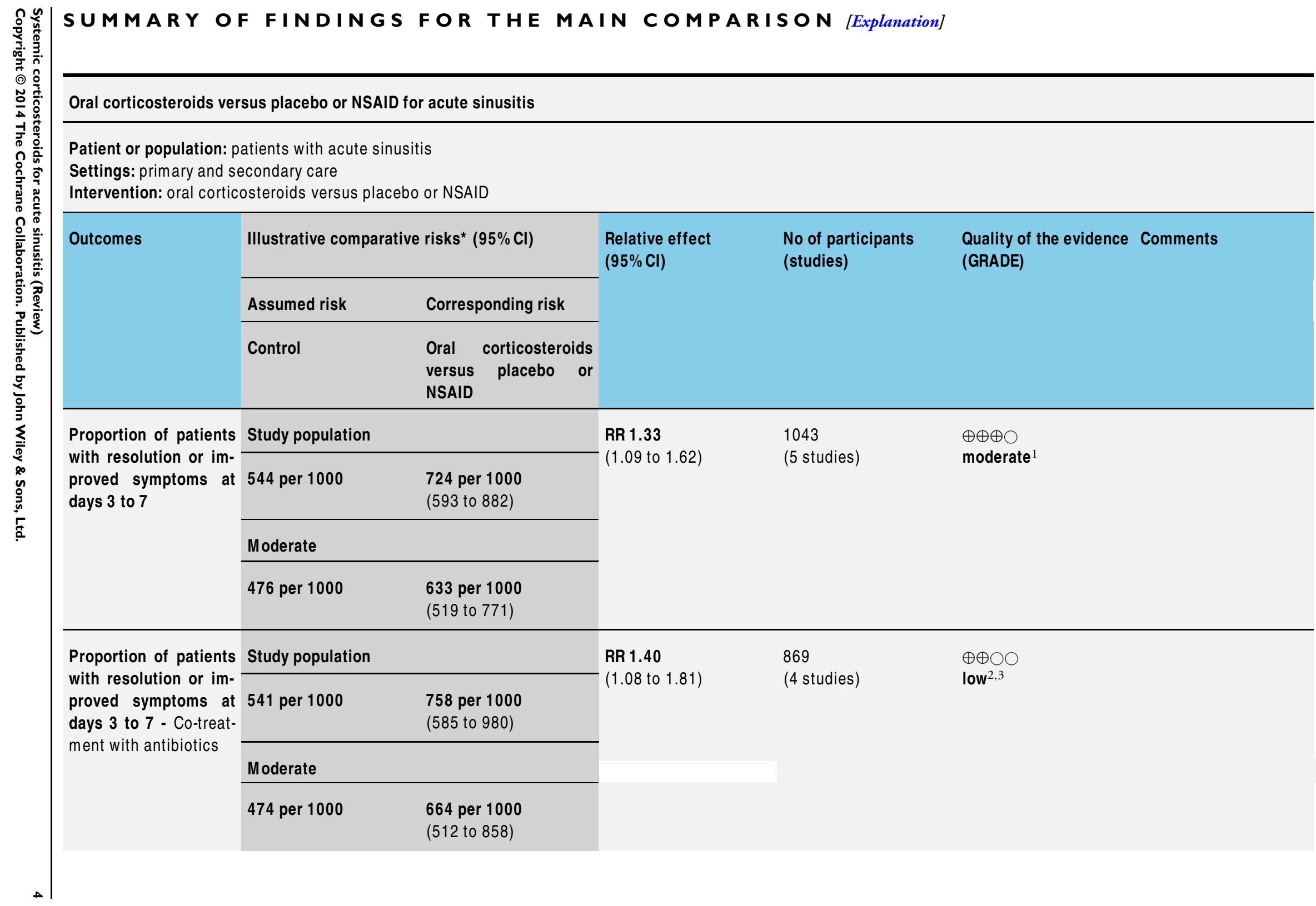




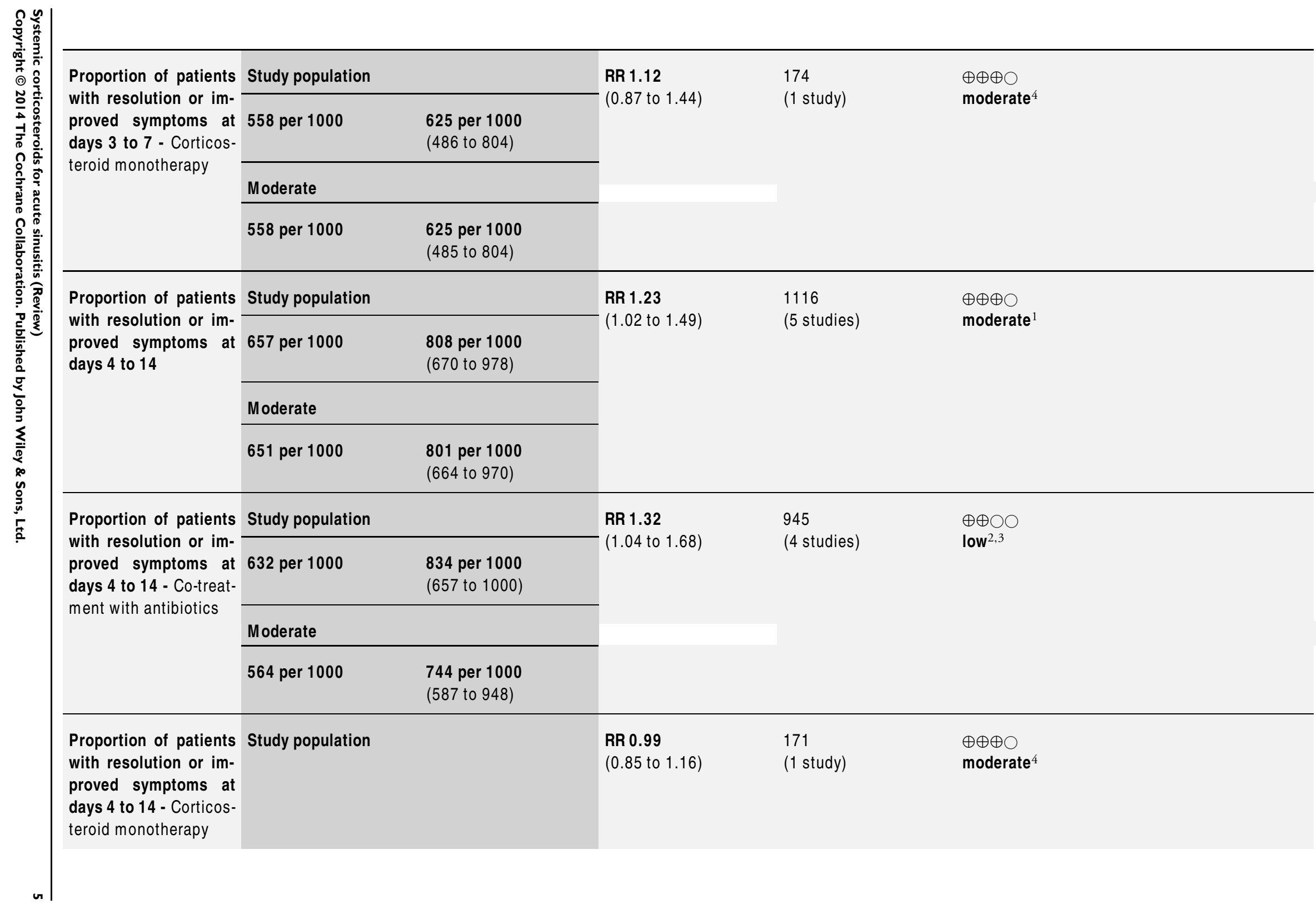




\begin{tabular}{ll}
\hline 798 per 1000 & $\begin{array}{l}790 \text { per } 1000 \\
(678 \text { to } 925)\end{array}$ \\
\hline
\end{tabular}

Moderate

798 per 1000

790 per 1000

(678 to 926$)$

Adverse events

No serious drug-related adverse events were reported in the 5 trials. 1193

$\oplus \oplus \oplus \bigcirc$

Adverse events were limited and mild (see Table 1) with no differences (5 studies)

moderate

between the systemic corticosteroid and the control treatment groups

*The basis for the assumed risk (e.g. the median control group risk across studies) is provided in footnotes. The corresponding risk (and its $95 \%$ confidence interval) is based on the assumed risk in the comparison group and the relative effect of the intervention (and its $95 \% \mathrm{Cl}$ ).

Cl: confidence interval; RR: risk ratio

GRADE Working Group grades of evidence

High quality: Further research is very unlikely to change our confidence in the estimate of effect.

Moderate quality: Further research is likely to have an important impact on our confidence in the estimate of effect and may change the estimate.

Low quality: Further research is very likely to have an important impact on our confidence in the estimate of effect and is likely to change the estimate.

Very low quality: We are very uncertain about the estimate.

${ }^{1}$ Methodological quality was judged moderate in four trials and high in one trial.

${ }^{2}$ Methodological quality of the four trials was judged moderate.

${ }^{3}$ Largest beneficial effect observed in one trial that used non-steroidal anti-inflammatory drug (NSAID) as control treatment.

${ }^{4}$ Only one trial with a wide confidence interval; unknown whether a larger trial would have been able to detect a (small)

beneficial effect of oral corticosteroids as a monotherapy.

${ }^{5}$ Trials not powered to detect (small) differences in adverse events between those receiving corticosteroids or control

treatment. However, none of the trials reported serious adverse events nor sinusitis-related complications. 


\section{B A C K G ROU N D}

Acute sinusitis is an important reason for primary care consultations, with typically 50 cases seen by a primary care doctor annually (Ashworth 2005; Kuyvenhoven 2006). This condition is associated with symptoms such as facial pain, headache and nasal congestion, which can be unpleasant for many people (Meltzer 2004). As a consequence, patients may seek medical attention in order to relieve symptoms and shorten the illness duration. Patients' misconceptions about the effectiveness of antibiotics in viral infections (Cals 2007) and physicians' overestimation of patients' expectations towards antibiotic prescriptions (Akkerman 2005b; Welschen 2004), along with the lack of specific knowledge about respiratory tract infections (Akkerman 2005a), are probably the main reasons for high antibiotic prescription rates in daily practice, ranging from approximately $60 \%$ in the Netherlands (Venekamp 2012b) to $92 \%$ in the United Kingdom (Ashworth 2005). However, a recent systematic review and a meta-analysis of individual data from randomised controlled trials (RCTs) showed that antibiotics are of limited use in patients with acute sinusitis (Ahovuo-Saloranta 2011; Young 2008). Acute sinusitis is therefore associated with both high direct and indirect healthcare costs and contributes to antimicrobial resistance.

\section{Description of the condition}

Acute sinusitis is defined as inflammation and swelling of the nasal and paranasal mucous membranes (Fokkens 2012; Snow 2001). It is thought that this mucosal swelling leads to obstruction of sinus openings and impairment of mucous drainage, sinus ventilation and mucociliary clearance, leading to the characteristic signs and symptoms of acute sinusitis such as purulent nasal discharge, nasal obstruction, reduction or loss of smell, headache, facial pain/pressure and/or dental pain (Fokkens 2012). In primary care settings, diagnosing acute sinusitis is usually based on signs and symptoms, since the diagnostic value of laboratory measurements (such as Creactive protein, erythrocyte sedimentation rate and white blood cell count) is low (Hansen 1995; Lindbaek 1996) and imaging (such as sinus X-ray and sinus ultrasound) leads to a high number of false positive and negative results (Laine 1998; Van Duijn 1992). The use of more advanced and invasive diagnostic tools such as nasal endoscopy, computed tomography (CT) scanning and sinus puncture are limited to secondary or tertiary care settings.

There is considerable debate about the aetiology of clinically diagnosed acute sinusitis. The condition was thought to be due to a bacterial infection of the paranasal sinuses (Piccirillo 2004). However, the majority of cases of acute sinusitis are likely to be caused by viral pathogens, since only $0.5 \%$ to $2 \%$ of viral upper respiratory tract infections are complicated by bacterial sinusitis (Berg 1986; Gwaltney 1996). Moreover, the results of a systematic review of RCTs with antibiotics have demonstrated only modest beneficial effect sizes (Ahovuo-Saloranta 2011), and a recent meta-analysis of individual patient data confirms that antibiotics are of limited use in clinically diagnosed acute sinusitis, even when patients do report signs and symptoms for 10 days or longer (Young 2008). As a consequence, acute inflammation of the paranasal mucosa due to (viral) pathogens might be the predominant common path in the causation of clinically diagnosed acute sinusitis (Snow 2001; Winstead 2003). Additionally, some studies suggest that non-infectious processes such as allergic inflammation and local eosinophilia may also play an important role (Baroody 2008; Kirtsreesakul 2004). Therefore, it is possible that anti-inflammatory therapy could provide attenuation of the host inflammatory response, leading to reductions in mucosal oedema and enhanced sinus clearance.

\section{Description of the intervention}

Corticosteroids inhibit transcription of pro-inflammatory mediators in human airway endothelial cells (Mygind 2001) and could potentially act as anti-inflammatory and decongestant agents. As a consequence, the use of corticosteroids might have beneficial effects in patients with common cold and acute sinusitis. A recent Cochrane review demonstrated that current limited evidence does not support the use of intranasal corticosteroids for symptomatic relief from the common cold (Hayward 2012b). Recent systematic reviews have assessed the role of intranasal but not systemic corticosteroids for acute sinusitis (Hayward 2012a; Zalmanovici 2011). One review found that for every 100 patients treated with intranasal corticosteroids, seven additional patients had complete or marked symptom relief at 15 to 21 days (number needed to treat to benefit $(\mathrm{NNTB})=15$ ) (Zalmanovici 2011), while the other review reported more or less similar results (for every 100 patients treated, eight additional patients had improvement or resolution of symptoms at 14 to 21 days, NNTB = 13) (Hayward 2012a). However, it was suggested that the effects of intranasal corticosteroids may be greater with high doses and with courses of 21 days' duration. In one of the included trials therapy tended to be more effective in mild than in severe cases, leading to the suggestion that thick secretions and severe inflammation in the nasal passages limited the effective topical delivery of the corticosteroids (Williamson 2007).

\section{How the intervention might work}

Systemic administration of corticosteroids might allow more effective delivery of corticosteroids to the nasal and paranasal mucosa than topical corticosteroids, providing increased anti-inflammatory effects. This could lead to a reduction in nasal oedema, mucus production and sinus blockage, which could result in symptomatic relief. Systemic corticosteroids (alone or as adjunctive treatment) are effective at reducing the severity of some acute respiratory tract 
infections such as croup (Russell 2011) and sore throat (Hayward 2009), as well as inflammatory conditions such as asthma and exacerbations of chronic obstructive airways disease (Schweiger 2010). When implementing systemic corticosteroid therapy in practice, physicians should be aware of the absence of specific contraindications including (active) peptic ulcer disease, history of depression or psychosis and immunodeficiency. Immunocompromised patients have an increased risk of bacterial (super)infection during viral (respiratory tract) infections and the use of systemic corticosteroids might further enhance this probability.

\section{Why it is important to do this review}

There has not been a systematic review of systemic corticosteroids for acute sinusitis. The beneficial effects of intranasal corticosteroids are modest but it is unclear if this is due to poor delivery of corticosteroids due to blocked nasal passages, or lack of an anti-inflammatory effect in acute sinusitis. This systematic review examines the effects of systemic corticosteroids in patients with acute sinusitis in order to provide a more definite answer on the use of corticosteroids for this condition.

\section{O B J E C T I V E S}

To assess the effects of systemic corticosteroids on clinical response rates and to determine adverse effects and relapse rates of systemic corticosteroids compared to placebo or standard clinical care in children and adults with acute sinusitis.

\section{METHODS}

\section{Criteria for considering studies for this review}

\section{Types of studies}

RCTs comparing systemic corticosteroids to placebo or standard clinical care.

\section{Types of participants}

Children and adults with acute sinusitis.

Acute sinusitis was defined by clinical diagnosis alone, or confirmed by additional radiological or nasal endoscopic examination. We excluded studies examining participants with a diagnosis of chronic sinusitis (defined as more than 12 weeks' duration) or other clear diagnoses (for example, common cold, nasal polyposis).

\section{Types of interventions}

Studies which used systemic corticosteroids versus placebo or standard clinical care in the control group. We included trials of corticosteroids delivered orally, or parenterally by intravenous or intramuscular injection. We excluded trials of corticosteroids delivered by the intranasal route or by inhalation.

We included trials reporting combined interventions (for example, co-treatment with antibiotics) if they allowed a direct comparison between the systemic corticosteroid and the control group and were unconfounded. By unconfounded, we mean studies where the two groups were not treated differently, except for the delivery of systemic corticosteroids to one group.

\section{Types of outcome measures}

\section{Primary outcomes}

1. Proportion of participants with resolution or improvement of any patient-related symptoms, including total change in clinical status, measured at two time points - short-term (two weeks or less) or long-term (more than two weeks).

\section{Secondary outcomes}

1. Time to resolution of symptoms.

2. Bacteriological cure and relapse rates.

3. Adverse events.

\section{Search methods for identification of studies}

\section{Electronic searches}

For this 2014 update of our 2011 review (Venekamp 2011), we searched the Cochrane Central Register of Controlled Trials (CENTRAL) (2014, Issue 1), which includes the Acute Respiratory Infections (ARI) Group's Specialised Register, MEDLINE (1966 to February week 1, 2014) and EMBASE (January 2009 to February 2014). There were no language or publication restrictions.

We combined the MEDLINE search with the Cochrane Highly Sensitive Search Strategy for identifying randomised trials in MEDLINE: sensitivity- and precision-maximising version (2008 revision) Ovid format (Lefebvre 2011). See Appendix 1 for the MEDLINE and CENTRAL search strategy and Appendix 2 for the EMBASE search strategy.

\section{Searching other resources}

To increase the yield of relevant studies, we inspected the reference lists of all identified studies and reviews. We searched the Database of Reviews of Effects (DARE) (Issue 1 of 4, January 2014) and the 
NHS Health Economics Database (EED) (Issue 1 of 4, January 2014), part of The Cochrane Library, www.thecochranelibrary.com (accessed 19 February 2014). We also searched the trials registries ClinicalTrials.gov and WHO ICTRP for completed and ongoing trials (accessed 19 February 2014).

\section{Data collection and analysis}

\section{Selection of studies}

In the first publication of this review (Venekamp 2011), two review authors (RV, MT) independently screened titles and abstracts from the electronic searches and reviewed the full text of the potentially relevant titles and abstracts against the inclusion and exclusion criteria. For this 2014 update, two review authors (RV, PG) independently completed these tasks.

\section{Data extraction and management}

In the first publication of this review (Venekamp 2011), two review authors (RV, MT) extracted data from the included trials and resolved disagreements by discussion. For this 2014 update, two review authors (GH, PG) extracted data from the included trials and resolved disagreements by discussion. We entered data into
RevMan 2012. We extracted the following information from each trial:

1. characteristics of trials: setting, design, method of dataanalysis;

2. participants: study population, number of participants in each group, patient characteristics such as age and gender;

3. type of intervention used: dosage, route of administration, duration of treatment and follow-up, compliance, cointerventions; and

4. outcomes: resolution or improvement of any patient-related symptoms, adverse events related to the intervention, drop-outs and reason(s) for dropping out.

\section{Assessment of risk of bias in included studies}

In the first publication of this review (Venekamp 2011), two review authors (RV, MT) independently assessed the methodological quality. For this 2014 update, two review authors (GH, PG) independently assessed the methodological quality. Any disagreements were resolved by discussion. Methodological quality assessment of the included studies was based on random sequence generation, allocation concealment, blinding, completeness of data and outcome assessment. Results of the 'Risk of bias' assessment are presented in the 'Risk of bias' tables (Higgins 2011). The overall risk of bias is summarised graphically in Figure 1. 
Figure I. 'Risk of bias' summary

\begin{tabular}{|c|c|c|c|c|c|c|}
\hline & 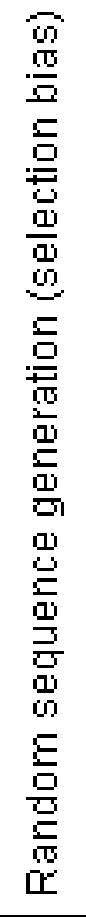 & 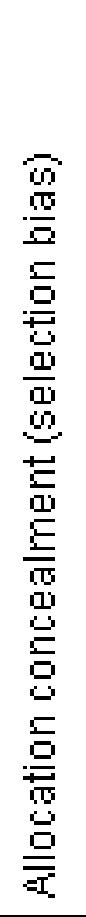 & 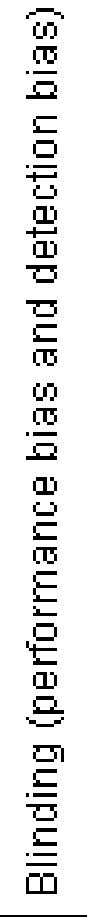 & 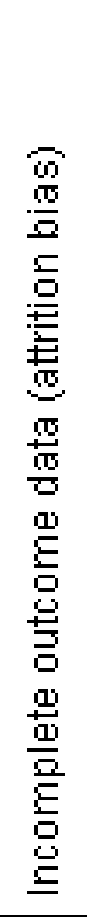 & 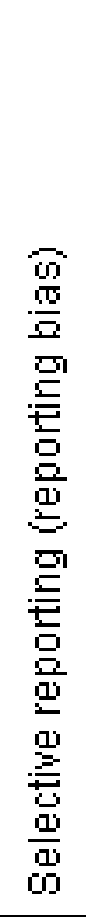 & 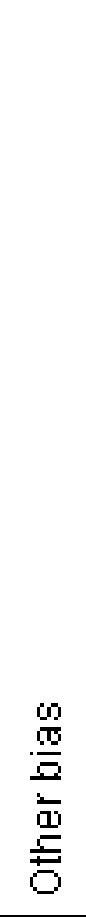 \\
\hline Cannoni 1990 & $?$ & $?$ & $?$ & $?$ & $?$ & $?$ \\
\hline Gehanno 2000 & $?$ & $?$ & $?$ & $?$ & $?$ & $?$ \\
\hline Klossek 2004 & $?$ & $?$ & $?$ & $?$ & $?$ & + \\
\hline Ratau 2004 & $\oplus$ & $?$ & $?$ & $?$ & $?$ & $?$ \\
\hline Venekamp 2012a & + & + & + & + & + & + \\
\hline
\end{tabular}




\section{Measures of treatment effect}

We performed intention-to-treat (ITT) analyses. We categorised the primary outcome (proportion of participants with resolution or improvement of individual clinical features) into short-term (two weeks or less) and long-term (more than two weeks). We expressed dichotomous outcomes as risk ratio (RR) and risk difference (RD) and calculated 95\% confidence intervals (CIs).

\section{Dealing with missing data}

We tried to contact the trial authors to provide additional information in case of missing data. In primary analyses, we only analysed the available data based on the ITT principle. We explored the impact of the incomplete data reporting on the validity of our results by performing scenario analyses (best and worst-case scenario). In the best-case scenario analyses all participants who were lost to follow-up in the treatment group were counted as treatment successes and all participants lost to follow-up in the control group were counted as treatment failures. In contrast, in the worstcase scenario analyses all participants who were lost to follow-up in the treatment group were counted as treatment failures and all participants lost to follow-up in the control group were counted as treatment successes.

\section{Assessment of heterogeneity}

We assessed clinical heterogeneity of the trials by reviewing differences across trials in study population, setting, intervention and outcome measures used. We used the $\mathrm{I}^{2}$ statistic to measure the level of statistical heterogeneity for each outcome, with $\mathrm{I}^{2}$ values over $50 \%$ suggesting substantial heterogeneity (Higgins 2003; Higgins 2011). We planned to consider five specific subgroups for subgroup analysis a priori (see Subgroup analysis and investigation of heterogeneity). We also performed sensitivity analyses by removing single trials to investigate the extent to which they contributed to the heterogeneity, particularly looking at reasons for clinical heterogeneity among the studies (e.g. type of control treatment).

\section{Assessment of reporting biases}

We assessed reporting biases using funnel plots (Figure 2).

Figure 2. Funnel plot of comparison: I Oral corticosteroids versus placebo or NSAID, outcome: I.I Proportion of patients with resolution or improved symptoms at days 3 to 7.

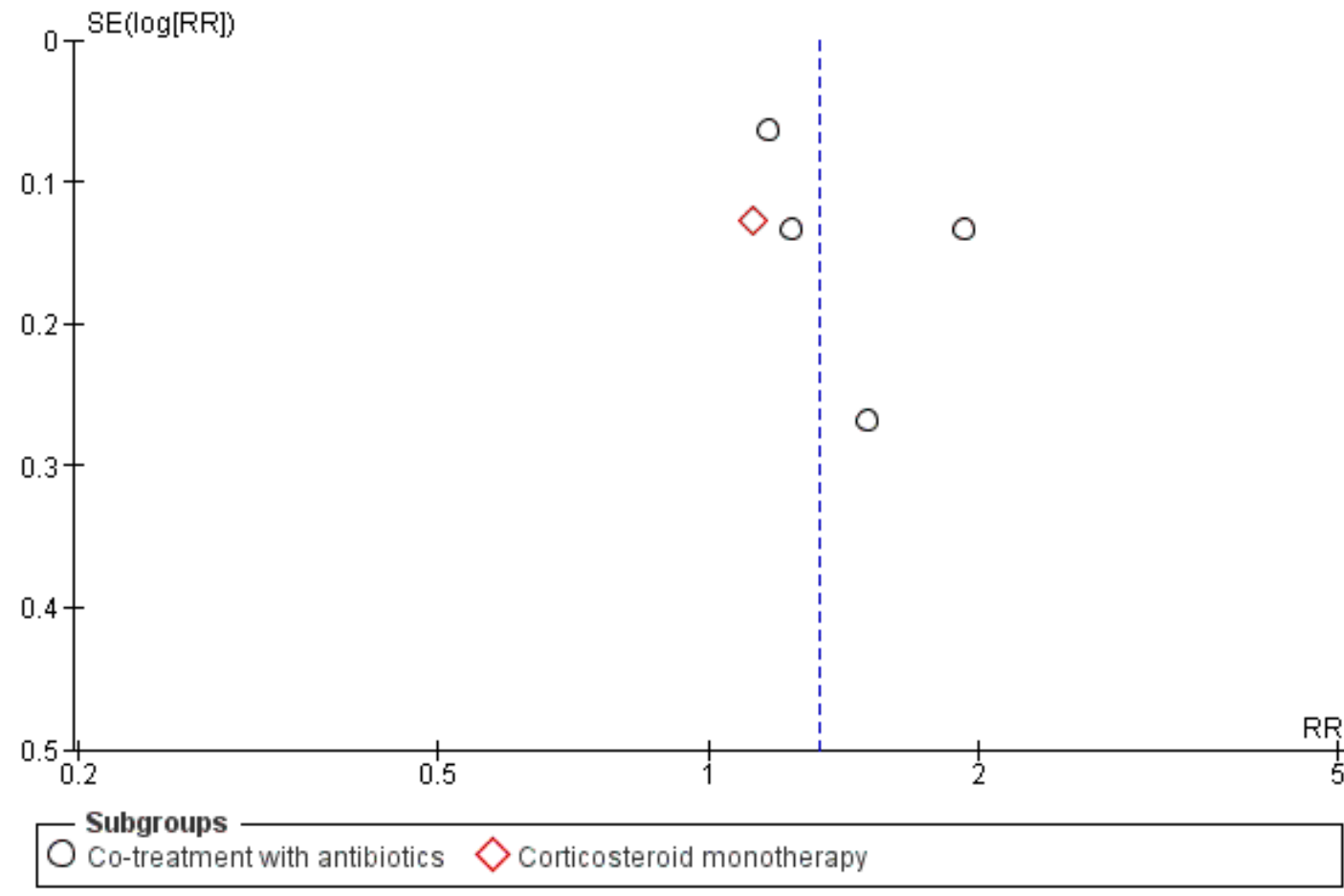




\section{Subgroup analysis and investigation of heterogeneity}

We planned to consider subgroup analyses for the following areas, if sufficient data were available:

1. adult/child;

2. type and route of delivery of corticosteroid;

3. duration and dose of corticosteroid;

4. radiological improvement versus clinical improvement; and

5. radiological versus clinical diagnosis.

We used a fixed-effect meta-analysis where no heterogeneity was present. If statistical heterogeneity was detected but unresolved by subgroup or sensitivity analysis, we used a random-effects model to provide a more conservative effect estimate.

\section{Sensitivity analysis}

We performed sensitivity analyses by removing single trials to investigate the extent to which they contributed to the heterogeneity, particularly looking at reasons for clinical heterogeneity of the studies (e.g. type of control treatment).

\section{RES U L T S}

\section{Description of studies}

\section{Results of the search}

This is an update of a Cochrane review first published in 2011 (Venekamp 2011). In the first version of our review, we retrieved a total of 2630 records from the initial search of CENTRAL, MEDLINE and EMBASE. Removing duplicates left 1710 records. After screening titles and abstracts, we identified seven potentially eligible studies. We obtained their full-text papers and excluded three trials as they studied chronic sinusitis (Ozturk 2011; Remer 2005; Vaidyanathan 2011). This left four trials eligible for inclusion (Cannoni 1990; Gehanno 2000; Klossek 2004; Ratau 2004). We identified no additional eligible trials after scanning the reference lists of full-text papers.

For this 2014 update, we retrieved a total of 630 records from the initial search of CENTRAL, MEDLINE, EMBASE, DARE and NHS EED. Removing duplicates left 529. After screening titles and abstracts we identified one potentially eligible study ( Venekamp 2012a). Based on full-text evaluation, we included this trial in our review as it fulfilled our predefined criteria. We did not identify any ongoing trials.

\section{Included studies}

Five trials with a total of 1193 participants involved adults only (Cannoni 1990; Gehanno 2000; Ratau 2004; Klossek 2004; Venekamp 2012a). One trial was a 2 x 2 factorial design (Gehanno 2000) and the other four were parallel designs (Cannoni 1990; Klossek 2004; Ratau 2004; Venekamp 2012a). In all five trials acute sinusitis was defined clinically. However, three trials also included radiological assessment as part of their inclusion criteria (Cannoni 1990; Gehanno 2000; Klossek 2004). Three studies performed in France included participants recruited from ENT outpatient clinics (Cannoni 1990; Gehanno 2000; Klossek 2004), one trial performed in South Africa included participants recruited from primary care clinics (Ratau 2004) and one trial included patients from primary care centres in the Netherlands (Venekamp 2012a).

Interventions in the trials included oral (methyl)prednisone (24 $\mathrm{mg}$ to $80 \mathrm{mg}$ ) for three, five and seven days and oral betamethasone $1 \mathrm{mg}$ for five days. The control group received a placebo in four studies (Gehanno 2000; Klossek 2004; Ratau 2004; Venekamp 2012a) and a non-steroidal anti-inflammatory drug (NSAID) in one study (Cannoni 1990). In four studies participants also received oral antibiotics: amoxicillin-clavulanic acid (Gehanno 2000; Ratau 2004), cefpodoxime (Klossek 2004) or pristinamycin (Cannoni 1990), while one trial investigated the effectiveness of oral corticosteroid monotherapy (Venekamp 2012a).

The use of analgesics (i.e. acetaminophen/paracetamol) was included as an outcome measure in two studies (Klossek 2004; Ratau 2004). No symptomatic relief medication was permitted in one study (Cannoni 1990), while no information on the use of additional medications was provided in one trial (Gehanno 2000). In one trial participants were allowed to use symptom relief medication (acetaminophen/paracetamol for as long as needed and xylometazoline $0.1 \%$ nasal spray for seven days).

The included studies reported the proportion of participants with therapeutic success on day seven (Cannoni 1990), proportions of participants experiencing pain relief on day four (Gehanno 2000), global response to treatment on day three and day 10 to 12 (Klossek 2004), improvement of symptoms from day zero to day six and the percentage of participants with physical signs present or absent on day zero and day six (Ratau 2004), and resolution of symptoms (including facial pain, nasal congestion, postnasal discharge and total symptoms) on day seven and day 14 (outcome data on facial pain/pressure at day 14 were not included in the original publication but were provided by the authors). All studies reported on the number of adverse events. In two studies the adverse events were reported both by patients (questionnaire) and investigator (at site visits) (Cannoni 1990; Klossek 2004), while the adverse events 
in the other studies were reported by the investigator (Gehanno 2000) or the patients (Ratau 2004; Venekamp 2012a) only. For more details on the outcome measures of the included studies see the Characteristics of included studies table.

\section{Excluded studies}

We excluded three trials after reviewing the full text, as they studied the effectiveness of systemic corticosteroids in participants with chronic sinusitis (Ozturk 2011; Remer 2005; Vaidyanathan 2011).

\section{Risk of bias in included studies}

We judged the methodological quality of the included trials to be moderate in four trials (Cannoni 1990; Gehanno 2000; Ratau 2004; Klossek 2004) and high in one trial (Venekamp 2012a) (see Figure 1). For details of the risk of bias in included studies see the 'Risk of bias' table (Characteristics of included studies).

\section{Allocation}

All five studies stated that they used randomisation, but we judged concealment of allocation to be adequate in only one trial (Venekamp 2012a). The methods of randomisation were unclear in three of the five trials (Cannoni 1990; Gehanno 2000; Klossek 2004). Additionally, only two trials reported baseline characteristics of participants (Klossek 2004; Venekamp 2012a).

\section{Blinding}

We considered all five trials to be double-blinded, but in four trials there were insufficient details to determine whether this referred to participants, outcome assessors or study personnel (Cannoni 1990; Gehanno 2000; Ratau 2004; Klossek 2004).

\section{Incomplete outcome data}

Four trials reported the numbers of participants who failed to complete the trial (Cannoni 1990; Gehanno 2000; Klossek 2004; Venekamp 2012a), whereas in one trial this was not reported and it was assumed that there were no drop-outs (Ratau 2004). The total loss to follow-up was low and varied from 4\% (Gehanno 2000), 6\% (Venekamp 2012a), 7\% (Cannoni 1990) to 8\% (Klossek 2004). In two of these studies the number of participants who were lost to follow-up was higher in the treatment group (Gehanno 2000; Klossek 2004), whereas in the other trials the drop-out rate was (slightly) higher in the control group (Cannoni 1990; Venekamp 2012a).

\section{Selective reporting}

In one trial (Venekamp 2012a) risk of reporting bias was judged low as pre-specified (primary and secondary) outcomes were listed in a trial register prior to study enrollment. In the other four trials (Cannoni 1990; Gehanno 2000; Klossek 2004; Ratau 2004) no study protocol was identified.

\section{Other potential sources of bias}

Three studies used ITT analyses (Gehanno 2000; Klossek 2004; Venekamp 2012a), while in the other two this was not clear (Cannoni 1990; Ratau 2004). Additionally, one trial did not provide information on absolute numbers of patients with resolution of symptoms as only percentages were reported (Ratau 2004). No other potential sources of bias could be detected in the five included trials.

\section{Effects of interventions}

See: Summary of findings for the main comparison Oral corticosteroids versus placebo or NSAID for acute sinusitis For numerical details see the Data and analyses section. We identified five studies that met our inclusion criteria, which included a total number of 1193 participants (Cannoni 1990; Gehanno 2000; Klossek 2004; Ratau 2004; Venekamp 2012a). From these trials, data from a total of 1116 participants could be extracted for meta-analyses for the primary outcome. The main findings are reported in Summary of findings for the main comparison.

\section{Primary outcomes}

\section{Proportion of participants with resolution or improvement of symptoms}

Information on the primary outcome could be retrieved from all five trials but at different time points. One trial reported global response to treatment on both day three and days 10 to 12 ( Klossek 2004), whereas the four other trials reported the outcome of interest at one point in time: the proportions of participants experiencing pain relief on day four (Gehanno 2000), proportions of participants with physical signs present or absent at day six ( Ratau 2004), therapeutic success at day seven (Cannoni 1990) and the proportion of patients with resolution of facial pain/pressure at day seven and day 14 (Venekamp 2012a). When combining data from the five trials, we calculated two effect estimates for the primary outcome, ranging from days three to seven (Cannoni 1990; Gehanno 2000; Klossek 2004; Ratau 2004; Venekamp 2012a) and days four to 14 (Cannoni 1990; Gehanno 2000; Klossek 2004; Ratau 2004; Venekamp 2012a).

Participants treated with oral corticosteroids were more likely to have short-term resolution or improvement of symptoms than 
those receiving the control treatment (placebo or non-steroidal anti-inflammatory drugs (NSAIDs)) at days three to seven (risk ratio (RR) $1.3,95 \%$ confidence interval (CI) 1.1 to 1.6 ; risk difference (RD) 17\%, 95\% CI 6\% to 29\%) (Analysis 1.1; Figure 3) and at days four to 14 (RR 1.2, 95\% CI 1.0 to 1.5 ; RD 14\%, $95 \%$ CI $1 \%$ to $27 \%$ ) (Analysis 1.2 ; Figure 4 ). Subgroup analyses revealed that oral corticosteroid monotherapy had no beneficial effects (Figure 3; Figure 4). Statistical heterogeneity was high in both of these analyses ( $\mathrm{I}^{2}$ statistic $\geq 69 \%$ ). We therefore performed a sensitivity analysis by removing the trial with NSAIDs as a control treatment (Cannoni 1990). Sensitivity analyses on the four trials with a placebo as the control treatment showed a similar direction of effect, but to a lesser extent, at days three to seven (RR 1.2, $95 \%$ CI 1.1 to 1.3 ; RD 11\%, 95\% CI 4\% to 17\%) (Analysis 2.1; Figure 5) and days four to 14 (RR 1.1, 95\% CI 1.0 to 1.2; RD 8\%, 95\% CI 2\% to 13\%) (Gehanno 2000; Klossek 2004; Ratau 2004; Venekamp 2012a) (Analysis 2.2; Figure 6). Statistical heterogeneity was lower in these sensitivity analyses $\left(\mathrm{I}^{2}\right.$ statistic $\leq$ $30 \%)$.

Figure 3. Forest plot of comparison: I Oral corticosteroids versus placebo or NSAID, outcome: I.I Proportion of patients with resolution or improved symptoms at days 3 to 7.

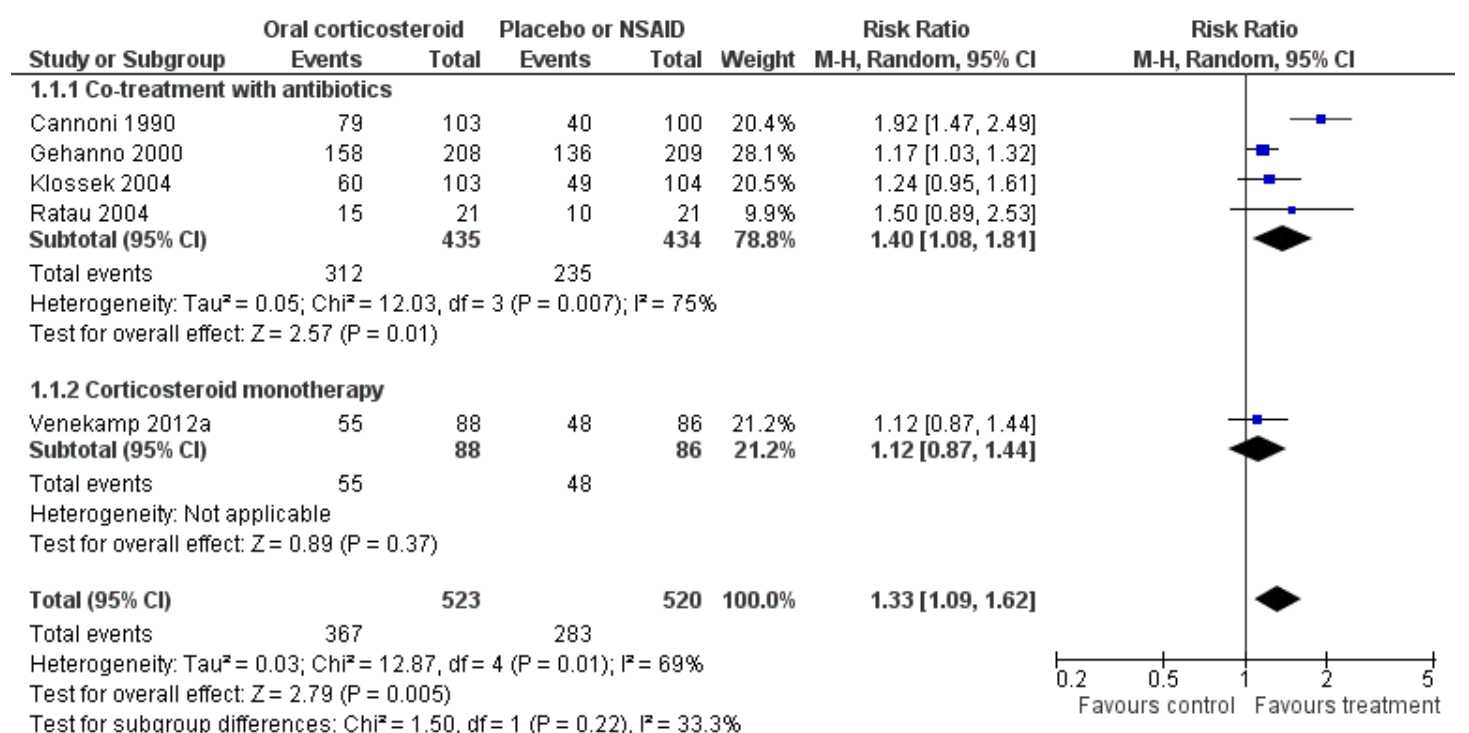


Figure 4. Forest plot of comparison: I Oral corticosteroids versus placebo or NSAID, outcome: I.2 Proportion of patients with resolution or improved symptoms at days 4 to 14 .

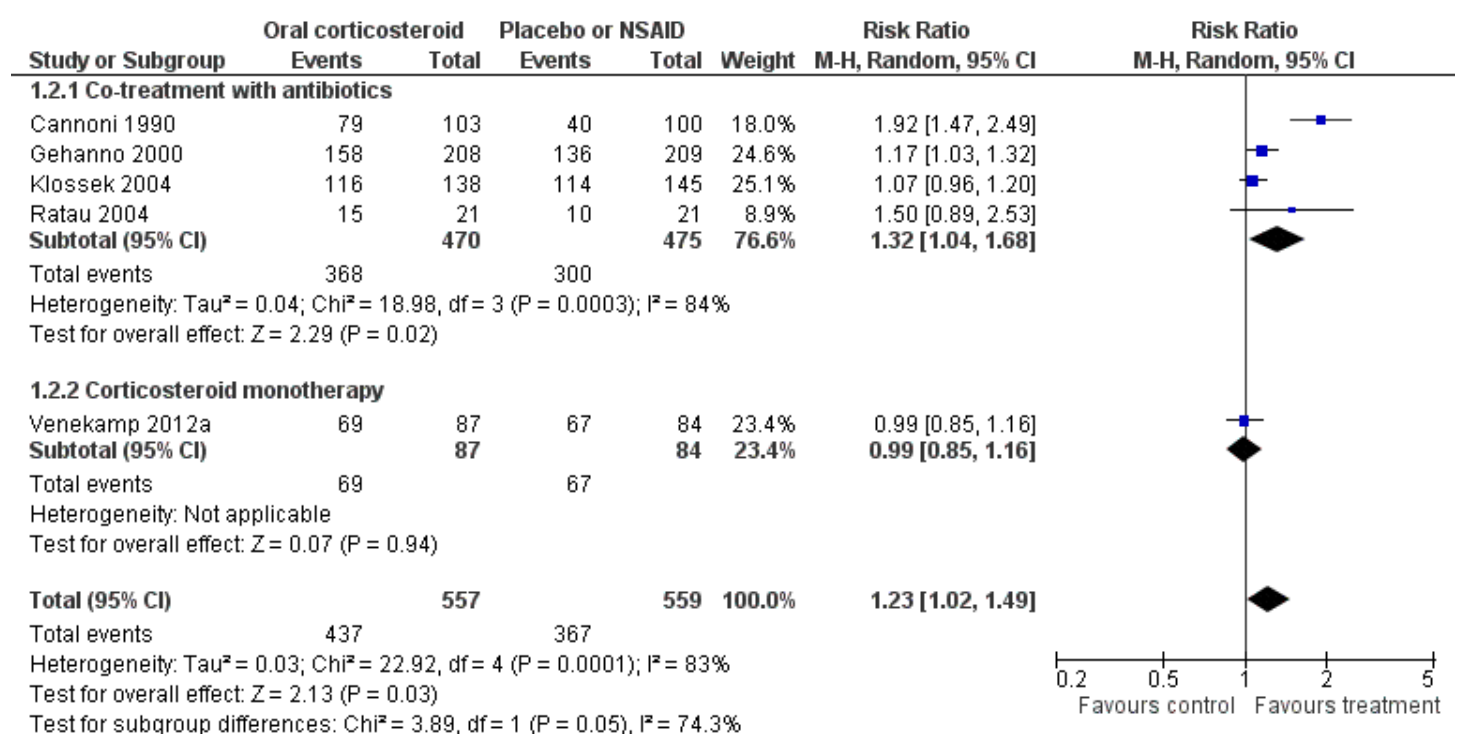

Figure 5. Forest plot of comparison: 2 Sensitivity analysis - Oral corticosteroids versus placebo, outcome: 2. I Proportion of patients with resolution or improved symptoms at days 3 to 7.

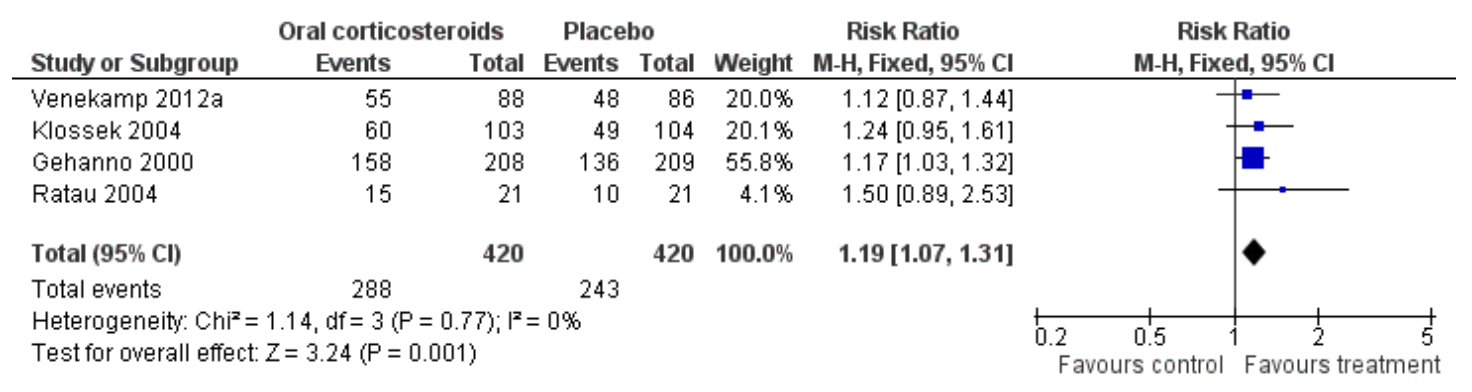


Figure 6. Forest plot of comparison: 2 Sensitivity analysis - Oral corticosteroids versus placebo, outcome: 2.2 Proportion of patients with resolution or improved symptoms at days 4 to I4.

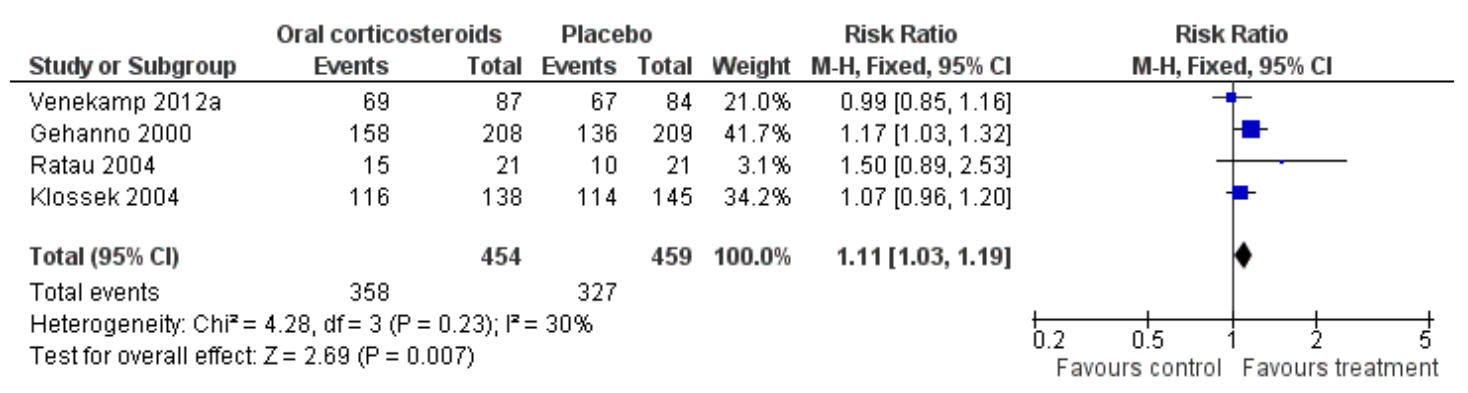

In scenario analyses, the best-case scenario did show increased beneficial effect sizes of oral corticosteroids for short-term relief (Analysis 3.1; Analysis 3.3; Analysis 4.1; Analysis 4.3), whereas the worst-case scenario showed no statistically significant beneficial effect of oral corticosteroids (Analysis 3.2; Analysis 3.4; Analysis 4.2; Analysis 4.4).

Only one trial reported on the long-term effects (more than two weeks) of oral corticosteroids (Venekamp 2012a). At eight weeks, the proportions of patients with resolution of facial pain/pressure and total symptoms were higher in the placebo group than in the oral corticosteroid monotherapy group, although the difference was not statistically significant (absolute risk difference (RD) $2.2 \%, 95 \%$ CI $-12.6 \%$ to $8.1 \%$ and $-9.9 \%, 95 \%$ CI $-24.7 \%$ to $4.9 \%$, respectively). No differences in the frequency of consultations for acute sinusitis between the oral corticosteroid monotherapy group (18/88) and the placebo group (21/86) were observed. In addition, neither of the groups differed significantly in the proportion of patients who received prescriptions for antibiotics (17/ 88 versus $16 / 86)$ or intranasal corticosteroids (6/88 versus $15 / 86)$.

\section{Secondary outcomes}

\section{Time to resolution of symptoms}

One trial reported this outcome (Venekamp 2012a). No statistically significant differences in median duration of symptoms were observed between the oral corticosteroid monotherapy group and the placebo group (facial pain/pressure 4.5 versus five days, nasal congestion four versus four days, postnasal discharge 3.5 versus three days, runny nose two days versus one day and total symptoms seven versus nine days), except for cough (two versus three days, $\mathrm{P}=0.046$ ).

\section{Bacteriological cure and relapse rates}

No data on these outcomes could be extracted from the trials.

\section{Adverse events}

No serious adverse events related to drug use were reported in the studies. There was no significant difference between the corticosteroid group and the placebo groups in the occurrence of mild adverse events (for example, abdominal pain, diarrhoea) or discontinuation of study treatment due to adverse events (Gehanno 2000; Klossek 2004; Ratau 2004; Venekamp 2012a). In one trial, seven adverse events were rated as severe by the patient: three in the corticosteroid group (one diarrhoea, one acute gastroenteritis, one abdominal pain) versus four in the placebo group (one vomiting, one abdominal pain, one neuralgia, one ear pain) (Ratau 2004). In the trial that used a NSAID as control group (Cannoni 1990), the number of adverse events was significantly higher in the NSAID group (51 adverse events in 35 participants) compared to the corticosteroid group ( 23 adverse events in 18 participants). In addition, discontinuation of study participation due to adverse events occurred in seven participants from the NSAID group versus none in the prednisolone group. For further details on adverse events see Table 1 .

\section{Subgroup analysis}

Subgroup analyses revealed that oral corticosteroid monotherapy had no statistically significant beneficial effects compared to placebo (Figure 3; Figure 4). We did not perform other subgroup analyses as the included trials did not report data for these prespecified subgroups.

\section{DISCUSSION}

\section{Summary of main results}

Five trials with a total of 1193 adult participants were included in this review. When combining the results of these studies, acute 
sinusitis patients treated with oral corticosteroids were more likely to have short-term improvement or resolution of symptoms than those receiving control treatment (placebo or non-steroidal antiinflammatory drugs (NSAIDs)) at days three to seven (risk difference (RD) 17\%) and days four to 14 (RD 14\%). Moreover, side effects of oral corticosteroids reported in these studies were limited and mild.

\section{Overall completeness and applicability of evidence}

Before applying these results to practice, there are important limitations which might have had an impact on our results.

Only five studies with a limited number of participants met the inclusion criteria for this review (Cannoni 1990; Gehanno 2000; Klossek 2004; Ratau 2004; Venekamp 2012a). Participants in four of the five included studies also received oral antibiotics (Cannoni 1990; Gehanno 2000; Klossek 2004; Ratau 2004). These trials reported on short-term outcomes only (less than two weeks). Moreover, the majority of the included patients in this review has been recruited in ENT outpatient clinics as only two of the five trials, including 227 participants, were performed in a primary care setting (Ratau 2004; Venekamp 2012a), and none of the trials reported on relapse rates of acute sinusitis. One high-quality trial investigated the effectiveness of oral corticosteroids as a monotherapy in 185 patients in primary care (of which 174 were analysed) (Venekamp 2012a). In contrast to the beneficial effects found in the four trials that assessed the effectiveness of systemic corticosteroids as adjunctive treatment to antibiotics, this latter trial found no statistically significant beneficial effects of systemic corticosteroids compared to placebo.

\section{Quality of the evidence}

We judged four included trials to be of moderate methodological quality (Cannoni 1990; Gehanno 2000; Ratau 2004; Klossek 2004), which might have led to biased estimates of effect. All trials stated that they were randomised and double-blinded but only one trial adequately reported the blinding procedure (Venekamp 2012a) and only two trials contained an adequate report of the generation of allocation sequence (Ratau 2004; Venekamp 2012a). Moreover, four of the five trials performed complete-case analysis (excluding participants who were lost to follow-up from their analysis), which might have important implications for the validity of their results since missing values are rarely completely at random. To investigate the potential impact of the incomplete data reporting on our results, we performed scenario analysis (best and worsecase scenarios). Scenario analyses showed that outcomes missing in the trials might have introduced attrition bias since the worstcase scenario showed no statistically significant beneficial effect of oral corticosteroids.

\section{Potential biases in the review process}

There was some clinical heterogeneity among the included trials. Acute sinusitis was defined clinically in all trials but the three trials performed in ENT outpatient clinics also included radiological assessment as part of their inclusion criteria. In addition, duration and dosage of the intervention (prednisolone for three, five and seven days ( $24 \mathrm{mg}$ to $80 \mathrm{mg}$ ) and betamethasone $1 \mathrm{mg}$ for five days), type of control treatment (one trial used non-steroidal anti-inflammatory drugs (NSAIDs) as a control treatment) and the follow-up time did vary across the studies. Additionally, all trials used different outcome assessments, varying from pain relief to global response to treatment. Combining multiple endpoints might lead to invalid results (type 1 error). However, the results of most of the separate studies are more or less equal. Furthermore, we performed subgroup analyses for trials with or without co-treatment with antibiotics. Nevertheless, one could argue that (statistical) heterogeneity in the primary analyses was too high to present pooled results ( $\mathrm{I}^{2}$ statistic $\geq 75 \%$ ). However, the consistency of the $\mathrm{I}^{2}$ statistic is known to be limited when only a few studies are available and subjective assessment could be made. To enhance the validity of our results, we performed additional analyses on the four trials with placebo as the control treatment. These analyses showed similar results to the primary analyses but with low (statistical) heterogeneity ( $\mathrm{I}^{2}$ statistic $\left.\leq 30 \%\right)$. In addition, we assessed funnel plots for potential reporting biases in the primary analysis (Figure 2). No asymmetry could be detected based on the five included trials.

\section{Agreements and disagreements with other studies or reviews}

No previous review on the use of systemic corticosteroids in acute sinusitis has been performed. Two systematic reviews on intranasal corticosteroids for acute sinusitis (with or without antibiotics) reported only modest beneficial effect sizes (for every 100 patients treated with intranasal corticosteroids, seven additional patients had complete or marked symptom relief at 15 to 21 days (number needed to treat to benefit $($ NNTB $)=15)$ ) (Zalmanovici 2011) and for every 100 patients treated, eight additional patients had improvement or resolution of symptoms at 14 to 21 days (NNTB = 13) (Hayward 2012a). Since we primarily evaluated the effects of systemic corticosteroids on short-term relief ( $<14$ days), a valid comparison between these reviews cannot be made. However, in a subsequent randomised controlled trial, performed in the primary care setting, intranasal corticosteroids as a monotherapy did not provide an overall beneficial effect in short-term symptom relief (Williamson 2007).

AUTHORS' CONCLUSIONS 


\section{Implications for practice}

Oral corticosteroids as a monotherapy appear to be ineffective for adult patients with clinically diagnosed acute sinusitis. Current data on the use of oral corticosteroids as an adjunctive therapy to oral antibiotics are limited: almost all trials are performed in secondary care and there is a significant risk of bias. This limited evidence suggests that oral corticosteroids in combination with antibiotics may be modestly beneficial for the short-term relief of symptoms in acute sinusitis, with a number needed to treat to benefit of seven for resolution or symptom improvement. Until further high-quality trials prove oral corticosteroids to be beneficial in patients with acute sinusitis, their use is not supported by robust evidence.

\section{Implications for research}

The only high-quality trial included in this review, performed in antibiotic-naive patients with clinically diagnosed acute sinusitis, found no statistically significant beneficial effects of systemic corticosteroids compared to placebo (Venekamp 2012a). The risk difference $(\mathrm{RD})$ for the primary outcome (proportion of patients with resolution of facial pain or pressure at day seven) was $6.7 \%$ ( $95 \%$ confidence interval (CI) $-7.9 \%$ to $21.2 \%$ ). This finding is at odds with our meta-analysis, which showed a benefit of oral corticosteroids on improvement or resolution of symptoms. The difference may reflect the fact that the effect of systemic corticosteroids alone is less than the effect of treatment with both systemic corticosteroids and antibiotics (resolution or improvement of symptoms at days three to seven: risk ratio (RR) $1.4,95 \%$ confidence interval (CI) 1.1 to 1.8 ; risk difference (RD) 20\%, 95\% CI 6\% to $34 \%$ (Figure 3 ) and resolution or improvement of symptoms at days four to 10 : RR $1.3,95 \%$ CI 1.0 to 1.7 ; RD $18 \%, 95 \% \mathrm{CI}$ $3 \%$ to $33 \%$ (Figure 4)), or that Venekamp 2012a may have been underpowered to detect a small beneficial effect of systemic corticosteroids. However, the four trials included in our meta-analysis that assessed oral corticosteroids in combination with antibiotics have a significant risk of bias (see Quality of the evidence) and therefore its results should be interpreted with caution. A large primary care factorial trial is needed to establish whether oral corticosteroids offer additional benefits to antibiotics alone in acute sinusitis.

Three of the four trials comparing the effects of antibiotics and oral corticosteroids to antibiotics alone included only patients with radiologically confirmed acute sinusitis and this may have enhanced the benefit seen with systemic corticosteroids. Meta-analyses of the effect of antibiotics in acute sinusitis have demonstrated different results when radiological assessment was part of the inclusion criteria, compared to clinical diagnosis alone (Ahovuo-Saloranta 2011; Young 2008). As such, we recommend that a computer tomography (CT) scan should be performed at baseline in all patients participating in a future primary care-based factorial trial on the effectiveness of oral corticosteroids and antibiotics, in order to derive a diagnostic model of patient characteristics, clinical signs, symptoms and additional point-of-care tests, which can accurately discriminate between a positive and negative CT scan (Damoiseaux 2008). If a simple and feasible prediction model could be derived, this may provide guidance to future studies evaluating the benefits of antibiotics, corticosteroids or both in a subgroup of patients with clinically diagnosed acute sinusitis.

\section{ACKNOWLEDGEMENTS}

We would like to thank the British Society for Antimicrobial Chemotherapy for a seed grant to assess treatment of common upper respiratory tract infections with corticosteroids.

The University Department of Primary Health Care is part of the National Institute of Health Research School of Primary Care Research, which provides financial support for senior investigators who contributed to this article. The opinions expressed are those of the review authors and not of the Department of Health.

We gratefully thank Sarah Thorning for her support with the search strategy and searches.

We thank the following people for commenting on the draft protocol: Anne Lyddiatt, Martin Desrosiers, Ian Williamson, Teresa Neeman and Roger Damoiseaux; and the following people for commenting on the draft review: Teddy Cheng, Ian Williamson, Pakpoom Supiyaphun, Conor Teljeur and Roger Damoiseaux.

Finally, we thank the following people for commenting on the draft of the 2014 update, which enabled us to improve the manuscript further: Rob Ware, Ian Williamson, Karim Elghanam, Jodi Duke and Roger Damoiseaux. 


\section{REFERE N C E S}

\section{References to studies included in this review}

\section{Cannoni 1990 \{published data only\}}

Cannoni M, Sambuc R, San Marco JL, Auquier P, Gorget C, Chiarelli P. Comparative study of the efficacy and tolerance of prednisolone versus niflumic acid in the treatment of acute sinusitis in adults [Étude comparative de l'efficacité et de la tolérance de la prednisolone versus acide niflumide dans le traitement des sinusites aiguës de l'adulte]. Annales d Oto-Laryngologie et de Chirurgie Cervico-Faciale 1990;107 (4):276-81. [PUBMED: 2221720]

Gehanno 2000 \{published data only\}

Gehanno P, Beauvillain C, Bobin S, Chobaut JC, Desaulty A, Dubreuil C, et al. Short therapy with amoxicillinclavulanate and corticosteroids in acute sinusitis: results of a multicentre study in adults. Scandinavian Journal of Infectious Diseases 2000;32(6):679-84. [PUBMED: 11200381]

Klossek 2004 \{published data only\}

Klossek JM, Desmonts-Gohler C, Deslandes B, Coriat F, Bordure P, Dubreuil C, et al. Treatment of functional signs of acute maxillary rhinosinusitis in adults. Efficacy and tolerance of administration of oral prednisone for 3 days [Traitement des signes fonctionnels des rhinosinusites maxillaires aiguës de l'adulte. Efficacité et tolérance de la prednisone administrée par voie orale pendant 3 jours]. Presse Médicale 2004;33(5):303-9. [PUBMED: 15041875]

Ratau 2004 \{published data only\}

Ratau NP, Snyman JR, Swanepoel C. Short-course, lowdose oral betamethasone as an adjunct in the treatment of acute infective sinusitis. Clinical Drug Investigation 2004;24 (10):577-82. [PUBMED: 17523719]

Venekamp 2012a \{published data only\}

Venekamp RP, Bonten MJ, Rovers MM, Verheij TJ, Sachs AP. Systemic corticosteroid monotherapy for clinically diagnosed acute rhinosinusitis: a randomized controlled trial. Canadian Medical Association Journal 2012;184: E751-7. [PUBMED: 22872770 ]

\section{References to studies excluded from this review}

Ozturk 2011 \{published data only\}

Ozturk F, Bakirtas A, Ileri F, Turktas I. Efficacy and tolerability of systemic methylprednisolone in children and adolescents with chronic rhinosinusitis: a double-blind, placebo-controlled randomized trial. Journal of Allergy and Clinical Immunology 2011;128(2):348-52. [PUBMED: 21624649]

Remer 2005 \{published data only\} Remer M, Polberg K, Obszanska B, Klatka J. Chronic sinusitis therapy with antibiotics (axetyl cefuroxym, clarithromycin) and steroid (prednisone). Polski Merkuriusz Lekarki 2005;19(111):343-4. [PUBMED: 16358864]

Vaidyanathan 2011 \{published data only\}

Vaidyanathan S, Barnes M, Williamson P, Hopkinson P, Donnan PT, Lipworth B. Treatment of chronic rhinosinusitis with nasal polyposis with oral steroids followed by topical steroids: a randomized trial. Annals of Internal Medicine 2011;154(5):293-302. [PUBMED: 21357906]

\section{Additional references}

\section{Ahovuo-Saloranta 2011}

Ahovuo-Saloranta A, Borisenko OV, Kovanen N, Varonen H, Rautakorpi UM, Williams JW Jr, et al. Antibiotics for acute maxillary sinusitis. Cochrane Database of Systematic Reviews 2011, Issue 3. DOI: 10.1002/ 14651858.CD000243.pub2

\section{Akkerman 2005a}

Akkerman AE, Kuyvenhoven MM, van der Wouden JC, Verheij TJ. Prescribing antibiotics for respiratory tract infections by GPs: management and prescriber characteristics. British Journal of General Practice 2005;55 (511):114-8. [PUBMED: 15720932]

Akkerman 2005b

Akkerman AE, Kuyvenhoven MM, van der Wouden JC, Verheij TJ. Determinants of antibiotic overprescribing in respiratory tract infections in general practice. Journal of Antimicrobial Chemotherapy 2005;56(5):930-6. [PUBMED: 16155062]

\section{Ashworth 2005}

Ashworth M, Charlton J, Ballard K, Latinovic R, Gulliford $\mathrm{M}$. Variations in antibiotic prescribing and consultation rates for acute respiratory infection in UK general practices 1995-2000. British Journal of General Practice 2005;55 (517):603-8. [PUBMED: 16105368 ]

\section{Baroody 2008}

Baroody FM, Mucha SM, DeTineo M. Nasal challenge with allergen leads to maxillary sinus inflammation. Journal of Allergy and Clinical Immunology 2008;121(5):1126-32. [PUBMED: 18367240]

Berg 1986

Berg O, Carenfelt C, Rystedt G, Anggård A. Occurrence of asymptomatic sinusitis in common cold and other acute ENT-infections. Rhinology 1986;24(3):223-5. [PUBMED: 3775189]

\section{Cals 2007}

Cals JW, Boumans D, Lardinois RJ, Gonzales R, Hopstaken RM, Butler CC, et al. Public beliefs on antibiotics and respiratory tract infections: an internet-based questionnaire study. British Journal of General Practice 2007;57(545): 942-7. [PUBMED: 18252068]

Damoiseaux 2008 Damoiseaux RA. Antibiotics for acute rhinosinusitis. Lancet 2008;372(9633):115; author reply 116 .

\section{Fokkens 2012}

Fokkens W, Lund V, Mullol J, European Position Paper on Rhinosinusitis and Nasal Polyps Group. European position 
paper on rhinosinusitis and nasal polyps 2012. Rhinology Supplement 2012;3:1-298. [PUBMED: 22764607]

\section{Gwaltney 1996}

Gwaltney JM Jr. Acute community-acquired sinusitis. Clinical Infectious Diseases 1996;23(6):1209-23. [PUBMED: 8953061]

\section{Hansen 1995}

Hansen JG, Schmidt H, Rosborg J, Lund E. Predicting acute maxillary sinusitis in a general practice population. BMJ 1995;311(6999):233-6. [PUBMED: 7627042]

\section{Hayward 2009}

Hayward G, Thompson M, Heneghan C, Perera R, Del Mar C, Glasziou P. Corticosteroids for pain relief in sore throat: systematic review and meta-analysis. BMJ 2009; 339:b2976. [PUBMED: 19661138]

\section{Hayward 2012a}

Hayward G, Heneghan C, Perera R, Thompson M. Intranasal corticosteroids in management of acute sinusitis: a systematic review and meta-analysis. Annals of Family Medicine 2012;10:241-9.

\section{Hayward 2012b}

Hayward G, Thompson MJ, Perera R, Del Mar CB, Glasziou PP, Heneghan CJ. Corticosteroids for the common cold. Cochrane Database of Systematic Reviews 2012, Issue 8. DOI: 10.1002/14651858.CD008116.pub2

\section{Higgins 2003}

Higgins JP, Thompson SG, Deeks JJ, Altman DG. Measuring inconsistency in meta-analyses. BMJ 2003;327 (7414):557-60. [PUBMED: 12958120]

\section{Higgins 2011}

Higgins JPT, Green S (editors). Cochrane Handbook for Systematic Reviews of Interventions Version 5.1.0 [updated March 2011]. The Cochrane Collaboration, 2011. Available from www.cochrane-handbook.org.

\section{Kirtsreesakul 2004}

Kirtsreesakul V, Naclerio RM. Role of allergy in rhinosinusitis. Current Opinion in Allergy and Clinical Immunology 2004;4(1):17-23. [PUBMED: 15090914]

\section{Kuyvenhoven 2006}

Kuyvenhoven M, Van Essen G, Schellevis F, Verheij T. Management of upper respiratory tract infections in Dutch general practice; antibiotic prescribing rates and incidences in 1987 and 2001. Family Practice 2006;23(2):175-9. [PUBMED: 16461445]

\section{Laine 1998}

Laine K, Määttä T, Varonen H, Mäkelä M. Diagnosing acute maxillary sinusitis in primary care: a comparison of ultrasound, clinical examination and radiography. Rhinology 1998;36(1):2-6. [PUBMED: 9569433]

\section{Lefebvre 2011}

Lefebvre C, Manheimer E, Glanville J. Chapter 6: Searching for studies. In: Higgins JPT, Green S editor(s). Cochrane Handbook for Systematic Reviews of Interventions Version 5.1.0 [updated March 2011]. The Cochrane Collaboration.
Available from www.cochrane-handbook.org. Chichester: Wiley-Blackwell, 2011.

\section{Lindbaek 1996}

Lindbaek M, Hjortdahl P, Johnson UL. Use of symptoms, signs and blood tests to diagnose acute sinus infections in primary care: comparison with computed tomography. Family Medicine 1996;28(3):183-8. [PUBMED: 8900550]

\section{Meltzer 2004}

Meltzer EO, Hamilos DL, Hadley JA, Lanza DC, Marple BF, Nicklas RA, et al. Rhinosinusitis: establishing definitions for clinical research and patient care. Journal of Allergy and Clinical Immunology 2004;114(Suppl 6): 155-212. [PUBMED: 15577865]

\section{Mygind 2001}

Mygind N, Nielsen LP, Hoffmann HJ, Shukla A, Blumberga G, Dahl R, et al. Mode of action of intranasal corticosteroids. Journal of Allergy and Clinical Immunology 2001;108(Suppl 1):16-25. [PUBMED: 11449202]

\section{Piccirillo 2004}

Piccirillo J. Clinical practice: acute bacterial sinusitis. New England Journal of Medicine 2004;351(9):902-10. [PUBMED: 15329428]

\section{RevMan 2012 [Computer program]}

The Nordic Cochrane Centre, The Cochrane Collaboration. Review Manager (RevMan). Version 5.2. Copenhagen: The Nordic Cochrane Centre, The Cochrane Collaboration, 2012.

\section{Russell 2011}

Russell KF, Liang Y, O'Gorman K, Johnson DW, Klassen TP. Glucocorticoids for croup. Cochrane Database of Systematic Reviews 2011, Issue 1. DOI: 10.1002/ 14651858.CD001955.pub3; PUBMED: 21249651

\section{Schweiger 2010}

Schweiger TA, Zdanowicz M. Systemic corticosteroids in the treatment of acute exacerbations of chronic obstructive pulmonary disease. American Journal of Health-system Pharmacy 2010;67(12):1061-9. [PUBMED: 20554591]

\section{Snow 2001}

Snow V, Mottur-Pilson C, Hickner JM. Principles of appropriate antibiotic use for acute sinusitis in adults. Annals of Internal Medicine 2001;134(6):495-7. [PUBMED: 11255527]

Van Duijn 1992

van Duijn NP, Brouwer HJ, Lamberts H. Use of symptoms and signs to diagnose maxillary sinusitis in general practice: comparison with ultrasonography. BMJ 1992;305(6855): 684-7. [PUBMED: 1298231]

\section{Venekamp 2012b}

Venekamp RP, Rovers MM, Verheij TJ, Bonten MJ, Sachs AP. Treatment of acute rhinosinusitis: discrepancy between guideline recommendations and clinical practice. Family Practice 2012;29:706-12. [PUBMED: 22389427]

Welschen 2004

Welschen I, Kuyvenhoven M, Hoes A, Verheij T. Antibiotics for acute respiratory tract symptoms: patients' expectations, 
GPs' management and patient satisfaction. Family Practice 2004;21(3):234-7. [PUBMED: 15128681]

\section{Williamson 2007}

Williamson IG, Rumsby K, Benge S, Moore M, Smith PW, Cross M, et al. Antibiotics and topical nasal steroid for treatment of acute maxillary sinusitis: a randomized controlled trial. JAMA 2007;298(21): 2487-96. [PUBMED: 18056902]

Winstead 2003

Winstead W. Rhinosinusitis. Primary Care 2003;30(1) 137-54. [PUBMED: 12825253]

\section{Young 2008}

Young J, De Sutter A, Merenstein D, van Essen GA, Kaiser L, Varonen H, et al. Antibiotics for adults with clinically diagnosed acute rhinosinusitis: a meta-analysis of individual patient data. Lancet 2008;371(9616):908-14. [PUBMED: 18342685]

\section{Zalmanovici 2011}

Zalmanovici A, Yaphe J. Intranasal steroids for acute sinusitis. Cochrane Database of Systematic Reviews 2011, Issue 8. DOI: 10.1002/14651858.CD005149.pub2;

PUBMED: 19821340

\section{References to other published versions of this review}

\section{Venekamp 2011}

Venekamp RP, Thompson MJ, Hayward G, Heneghan CJ, Del Mar CB, Perera R, et al. Systemic corticosteroids for acute sinusitis. Cochrane Database of Systematic Reviews 2011, Issue 12. DOI: 10.1002/14651858.CD008115.pub2

* Indicates the major publication for the study 


\section{CHARACTERISTICS OFSTUDIES}

\section{Characteristics of included studies [ordered by study ID]}

\section{Cannoni 1990}

Methods

Randomisation: yes, method of randomisation not described

Concealment of allocation: not described

Double-blind: yes, blinding procedure not described

Intention-to-treat (ITT): unclear

Loss to follow-up: described; 203 patients (93\%) completed study

Design: parallel

Narticipants 219
Age: 15 to 70 years
Inclusion criteria: (sub)acute, non-allergic sinusitis confirmed by radiologic examina-
tion and nasal endoscopy
Exclusion criteria: allergic sinusitis (allergic rhinitis, nasal polyposis), previous sinonasal
surgery, contraindication to study treatment and treatment with corticosteroids, antibi-
otics or NSAIDs in 15 days preceding recruitment
Baseline characteristics: not described
Participants recorded symptoms twice a day and were examined at day 0 and day 7 of
treatment

Interventions

All participants in both groups received pristinamycin (antibiotic) $1000 \mathrm{mg}$ twice daily Tx: prednisolone $40 \mathrm{mg}$ once daily for participants with a weight $<60 \mathrm{~kg}$ and prednisolone $60 \mathrm{mg}$ once daily for participants with a weight $>60 \mathrm{~kg}$, for 7 days; $\mathrm{N}=107$ ( $\mathrm{N}=103$ included in analysis)

C group: niflumic acid (NSAID) $250 \mathrm{mg} 3$ daily for 7 days; $\mathrm{N}=112$ ( $\mathrm{N}=100$ included in analysis)

Use of additional medication: other anti-inflammatory drugs, intranasal medication and analgesics were not permitted

Outcomes

Primary outcome: therapeutic success, defined as a combination of resolution of spontaneous pain, absence of sinus pain on palpation, absence of nasal discharge or nasal discharge without purulence and a clean appearance of the middle meatus at nasal endoscopy at day 7 of treatment

Secondary outcome: adverse events

Notes

Setting: secondary care setting in France, 50 otorhinolaryngologists

Drop-outs total: $16 / 219(7 \%)$

Drop-outs from Tx: 4 (3.7\%) - 4 loss to follow-up

Drop-outs from C group: 12 (12.7\%): 2 loss to follow-up, 7 adverse events, 3 ineffectiveness

Source of funding: unknown

\section{Risk of bias}

Bias 
Cannoni 1990 (Continued)

Random sequence generation (selection Unclear risk

Randomisation method not described

bias)

\begin{tabular}{|c|c|c|}
\hline Allocation concealment (selection bias) & Unclear risk & Not described \\
\hline $\begin{array}{l}\text { Blinding (performance bias and detection } \\
\text { bias) } \\
\text { All outcomes }\end{array}$ & Unclear risk & Blinding procedure not described \\
\hline $\begin{array}{l}\text { Incomplete outcome data (attrition bias) } \\
\text { All outcomes }\end{array}$ & Unclear risk & Complete-case analysis performed \\
\hline Selective reporting (reporting bias) & Unclear risk & Study protocol not identified \\
\hline Other bias & Unclear risk & $\begin{array}{l}\text { ITT analysis - unclear. Baseline characteris- } \\
\text { tics - not described. Use of analgesics - not } \\
\text { permitted }\end{array}$ \\
\hline
\end{tabular}

Gehanno 2000

Methods

Randomisation: yes, method of randomisation not described

Concealment of allocation: not described

Double-blind: yes, blinding procedure not described

Intention-to-treat (ITT): yes

Loss to follow-up: described; 417 patients (96\%) completed study

Design: 2 × 2 factorial design

Participants

Interventions
N: 433

Age: 18 years or older

Inclusion criteria: less than 10 days of acute sinusitis defined by craniofacial pain, purulent nasal discharge with purulent drainage from the middle meatus, and opacities with or without air-fluid levels on standard X-ray or CT scan

Exclusion criteria: acute sinusitis requiring immediate surgical drainage, acute exacerbations of chronic sinusitis, contraindication to study treatment and treatment with antibiotics or corticosteroids in 15 days preceding recruitment

Baseline characteristics: not described

Participants were contacted by telephone on day $4+/-1$ to evaluate craniofacial pain, nasal discharge and temperature. A clinical and radiological follow-up was performed on day $14+/-2$, including an assessment of safety. Finally, the patient was contacted again by telephone on day $30+/-2$ to evaluate craniofacial pain, nasal discharge and temperature

From days 0 to 5, all participants received amoxicillin-clavulanic acid (ACA) $500 \mathrm{mg} 3$ times a day

From days 0 to 5 , participants randomised to either:

Tx: methylprednisolone $8 \mathrm{mg} 3$ times daily; $\mathrm{N}=219$ ( $\mathrm{N}=208$ included in ITT analysis)

, or

C group: placebo; $\mathrm{N}=214$ ( $\mathrm{N}=209$ included in ITT analysis $)$ 
From days 6 to 10, participants randomly received either ACA $500 \mathrm{mg} 3$ times a day or placebo

Use of additional medication: not described

Outcomes

Notes
Primary outcome: therapeutic success, defined as clinical recovery on day 14, with or without radiological normalisation. The other cases were considered failures

Secondary outcomes: i) course of symptoms on day 4 ii) symptoms and possible radiological signs on day 30

The study was primarily designed to determine the optimal duration of antibiotic treatment by comparing various durations of treatment with ACA. As the effectiveness of short-course corticosteroid was of secondary interest in this study, only data on day 4 of treatment are provided

Setting: secondary care setting in France, 51 otorhinolaryngologists

Drop-outs total: $16 / 433(4 \%)$ - lack of data 13; protocol violation 3

Drop-outs from Tx: $11(5.0 \%)$

Drop-outs from C group: 5 (2.3\%)

Source of funding: commercial - SmithKline Beecham

\section{Risk of bias}

\begin{tabular}{|c|c|c|}
\hline Bias & Authors' judgement & Support for judgement \\
\hline $\begin{array}{l}\text { Random sequence generation (selection } \\
\text { bias) }\end{array}$ & Unclear risk & Randomisation method not described \\
\hline Allocation concealment (selection bias) & Unclear risk & Not described \\
\hline $\begin{array}{l}\text { Blinding (performance bias and detection } \\
\text { bias) } \\
\text { All outcomes }\end{array}$ & Unclear risk & Blinding procedure not described \\
\hline $\begin{array}{l}\text { Incomplete outcome data (attrition bias) } \\
\text { All outcomes }\end{array}$ & Unclear risk & Complete-case analysis performed \\
\hline Selective reporting (reporting bias) & Unclear risk & Study protocol not identified \\
\hline Other bias & Unclear risk & $\begin{array}{l}\text { ITT analysis - yes. Baseline characteristics } \\
\text { - not described. Use of analgesics - not de- } \\
\text { scribed }\end{array}$ \\
\hline
\end{tabular}


Methods
Randomisation: yes, method of randomisation not described

Concealment of allocation: not described

Double-blind: yes, blinding procedure not described

Intention-to-treat (ITT): yes

Loss to follow-up: yes, reasons not described; 289 participants (92\%) completed study Design: parallel
Interventions

\section{N: 314}

Age: 18 years or older

Inclusion criteria: acute sinusitis, confirmed by X-ray and nasal endoscopy, for less than 5 days, with spontaneous pain assessed as $>50 \mathrm{~mm}$ on a visual analogue scale (VAS)

Exclusion criteria: acute sinusitis requiring immediate surgical drainage, allergic rhinitis, nasal polyposis, contraindication to study treatment, treatment with antibiotics in previous 3 months or (intranasal or systemic) corticosteroids in 3 days preceding recruitment

Baseline characteristics: balanced

Patients underwent X-ray and nasal endoscopic examination at day 1, day 10 to 12 and day 28 to 32 . Participants recorded symptoms from day 1 to 3 and were contacted by telephone on day 4

All participants received cefpodoxime (antibiotic) $200 \mathrm{mg}$ twice daily from days 1 to 10 Tx: prednisone 0.8 to $1.2 \mathrm{mg} / \mathrm{kg}$ (weight 40 to $60 \mathrm{~kg}$ : $40 \mathrm{mg}$, weight 60 to $80 \mathrm{~kg}$ : 60 $\mathrm{mg}$, weight $>80 \mathrm{~kg}: 80 \mathrm{mg}$ ) for 3 days; $\mathrm{N}=157$ ( $\mathrm{N}=142$ included in ITT analysis) C group: placebo; $\mathrm{N}=157$ ( $\mathrm{N}=147$ included in ITT analysis)

Use of additional medication: paracetamol $1000 \mathrm{mg}$ 8-hourly for pain as needed, other symptomatic relief medication not described

Outcomes

Primary outcome: mean of the differences between pain at baseline and day 3 measured using the VAS (this was termed the mean pain intensity difference - MPID)

Secondary outcomes: i) mean of the differences in intensity of nasal obstruction, ii) time lapse before the orally expressed relief of pain (pain relief intensity difference - PRID), iii) administration of paracetamol during the first 3 days, iv) global effect of treatment scored by patient at day 3, v) global effect of treatment scored by participant at day 10 to 12

Notes

Setting: secondary care setting in France, 80 otorhinolaryngologists

Drop-outs total: $25 / 314(8 \%)$ - reasons unknown

Drop-outs from Tx: $15(9.5 \%)$

Drop-outs from C group: 10 (6.4\%)

Source of funding: unknown

\section{Risk of bias}

\begin{tabular}{l|l|l}
\hline Bias & Authors' judgement & Support for judgement \\
\hline $\begin{array}{l}\text { Random sequence generation (selection } \\
\text { bias) }\end{array}$ & Unclear risk & Randomisation method not described \\
\hline
\end{tabular}

$\begin{array}{lll}\text { Allocation concealment (selection bias) Unclear risk } & \text { Not mentioned }\end{array}$ 
bias)

All outcomes

\begin{tabular}{l|ll}
\hline $\begin{array}{l}\text { Incomplete outcome data (attrition bias) } \\
\text { All outcomes }\end{array}$ & Unclear risk & $\begin{array}{l}\text { Reasons for drop-outs not reported, com- } \\
\text { plete-case analysis performed }\end{array}$ \\
\hline Selective reporting (reporting bias) & Unclear risk & Study protocol not identified \\
\hline Other bias & Low risk & $\begin{array}{l}\text { ITT analysis - yes. Baseline characteristics } \\
\text { - balanced. Use of analgesics - noted (sec- } \\
\text { ondary outcome) }\end{array}$ \\
\hline
\end{tabular}

Ratau 2004

\begin{tabular}{ll}
\hline Methods & Randomisation: yes, computer-generated random numbers \\
& Concealment of allocation: not described \\
Double-blind: yes, blinding procedure not described \\
Intention-to-treat (ITT): unclear \\
Loss to follow-up: not described \\
Design: parallel \\
\hline
\end{tabular}

Participants

Interventions

\section{N: 42}

Age: 29 years (mean age)

Inclusion criteria: clinically defined acute sinusitis for less than 12 weeks. Total symptom score (7 symptoms, scored 0 to 3 severity, to maximum score of 21) was 6 or higher, at least 1 nasal symptom had to be moderate or severe and purulent rhinorrhoea or postnasal drip had to be present

Exclusion criteria: nasal polyposis, abnormalities of the nose, contraindication to study treatment, treatment with antibiotics, anti-inflammatory agents, oral corticosteroids in previous 4 weeks or intranasal corticosteroids in 2 weeks preceding recruitment

Baseline characteristics: not described

Participants evaluated symptoms each evening for 5 days in a diary and recorded the use of paracetamol and adverse events. Investigator scored signs and symptoms on the day of diagnosis (day 0) and on the second visit (day 6)

All participants received amoxicillin-clavulanic acid $625 \mathrm{mg} 3$ times a day for 5 days Tx: betamethasone $1 \mathrm{mg}$ orally once daily for 5 days; $\mathrm{N}=21$

C group: placebo; $\mathrm{N}=21$

Use of additional medication: analgesics permitted, paracetamol $1000 \mathrm{mg}$ 6-hourly for pain as needed, other symptomatic relief medication (i.e. oral decongestants, antihistamines and mucolytics) not permitted

Outcomes

Primary outcome: improvement of symptoms from day 0 to day 6 (change in treatment effects)

Secondary outcomes: i) percentage of participants with physical signs present or absent on day 0 and day 6 , ii) number of paracetamol tablets taken, iii) adverse events 
Notes

Setting: 3 primary healthcare sites in Republic of South Africa, 2003

Drop-outs: not described

Source of funding: non-commercial (Department of Pharmacology, University of Pretoria); drugs were supplied by pharmaceutical companies (betamethasone - ScheringPlough; amoxicillin-clavulanic acid - Rolab Pharmaceuticals)

\section{Risk of bias}

\begin{tabular}{|c|c|c|}
\hline Bias & Authors' judgement & Support for judgement \\
\hline $\begin{array}{l}\text { Random sequence generation (selection } \\
\text { bias) }\end{array}$ & Low risk & $\begin{array}{l}\text { Randomisation method - computed-gen- } \\
\text { erated random numbers }\end{array}$ \\
\hline Allocation concealment (selection bias) & Unclear risk & Not mentioned \\
\hline $\begin{array}{l}\text { Blinding (performance bias and detection } \\
\text { bias) } \\
\text { All outcomes }\end{array}$ & Unclear risk & Blinding procedure not mentioned \\
\hline $\begin{array}{l}\text { Incomplete outcome data (attrition bias) } \\
\text { All outcomes }\end{array}$ & Unclear risk & Not described \\
\hline Selective reporting (reporting bias) & Unclear risk & Study protocol not identified \\
\hline Other bias & Unclear risk & $\begin{array}{l}\text { ITT analysis - unclear. Baseline-character- } \\
\text { istics - not described. Outcome measures - } \\
\text { only percentages, no absolute numbers pro- } \\
\text { vided. Use of analgesics - noted (secondary } \\
\text { outcome) }\end{array}$ \\
\hline
\end{tabular}

Venekamp 2012a

Rethods
Randomisation: yes, block randomisation using computer-generated random numbers
Concealment of allocation: adequate
Double-blind: yes
Intention-to-treat (ITT): yes
Loss to follow-up: described; 174 patients $(94 \%)$ completed study
Design: parallel

Participants $\quad$ N: 185

Age: 18 years and older

Inclusion criteria: symptoms of acute sinusitis (at least 2 symptoms: 1 of either nasal discharge (anterior or posterior nasal drip) or nasal congestion; the other of either facial pain or pressure, or pain when masticating) for at least 5 days

Exclusion criteria: complicated course of acute sinusitis (i.e. orbital swelling, temperature $\geq 38.5^{\circ} \mathrm{C}$ after 5 days of symptoms) recurrent sinusitis ( $\geq 2$ episodes in the previous year), pregnancy, previous ENT surgery for malignant disease, contraindication to treatment with corticosteroids and use of (intranasal or oral) corticosteroids in 4 weeks 


\begin{tabular}{ll} 
& $\begin{array}{l}\text { preceding recruitment } \\
\text { Baseline characteristics: balanced } \\
\text { Participants recorded symptoms in a daily diary for } 14 \text { days and were examined at day } \\
0 \text { and day } 14 \text { of treatment. At the end of follow-up (8 weeks after randomisation), } \\
\text { physicians were asked to complete a final questionnaire about consultations in the past } \\
6 \text { weeks and patients were contacted by telephone by the study physician to complete a } \\
\text { questionnaire }\end{array}$ \\
\hline Interventions & $\begin{array}{l}\text { Tx: prednisolone } 30 \text { mg once daily for } 7 \text { days; } \mathrm{N}=93(\mathrm{~N}=88 \text { included in analysis) } \\
\text { C group: placebo for } 7 \text { days; } \mathrm{N}=92 \text { ( } \mathrm{N}=86 \text { included in analysis) } \\
\text { Use of additional medication: participants were allowed to take acetaminophen/parac- } \\
\text { etamol } 500 \text { mg (maximum of } 6 \text { tablets per day) for as long as needed and xylometazoline } \\
0.1 \% \text { nasal spray for } 7 \text { days }\end{array}$ \\
\hline
\end{tabular}

Outcomes

Primary outcome: proportion of patients with resolution of facial pain/pressure at day 7 of treatment

Secondary outcome: the proportion of patients with resolution of other clinically relevant symptoms on day 7, time to resolution of total symptoms (combined symptoms of runny nose, postnasal discharge, nasal congestion, cough and facial pain), median duration of symptoms, health-related quality of life and resumption of daily activities (work or school)

Outcome data (proportion of patients with resolution of facial pain/pressure) at day 14 was not included in the original CMAJ publication but has been provided by the authors

Setting: 54 primary care centres in the Netherlands
Drop-outs total: $11 / 185(5.9 \%)$
Drop-outs from Tx: $5 / 93(5.4 \%)-1$ withdrawal from study, 3 no diary returned, 1
incomplete symptom reporting
Drop-outs from C group: $6 / 92(6.5 \%): 1$ withdrawal from study, 2 no diary returned,
3 incomplete symptom reporting
Source of funding: non-commercial, grant from the Netherlands Organisation for
Health Research and Development

\section{Risk of bias}

Bias

Authors' judgement

Random sequence generation (selection Low risk bias)

Allocation concealment (selection bias) Low risk

\section{Support for judgement}

Computer-generated block randomisation in blocks of 4

Sealed, blind-sequenced medication containers were distributed to participating practices. The containers were identifiable only by randomisation code number. The pharmacy department of the University Medical Center Utrecht (independent of the trial team) created the block randomisation sequence using computer-generated random numbers. The randomisation code 
Venekamp 2012a (Continued)

was kept at a locker in the pharmacy department throughout the study

Blinding (performance bias and detection Low risk bias)

All outcomes

All outcomes
Sealed, blind-sequenced medication containers were distributed to participating practices. The containers were identifiable only by randomisation code number. The randomisation code was kept at a locker in the pharmacy department throughout the study and was not broken until data collection was completed and blinded analyses were performed. Study medications were identical in taste and appearance

Reasons for drop-out reported. Primarily complete-case analysis was performed but in sensitivity analysis missing data were imputed using multiple imputation. Primary and sensitivity analysis showed similar results

Selective reporting (reporting bias) Low risk

Pre-specified (primary and secondary) outcomes are listed in Netherlands Trial Register, NTR1295

ITT analysis - yes. Baseline characteristics - balanced. Use of analgesics - allowed

ACA: amoxicillin-clavulanic acid

C group: control group

CMAJ: Canadian Medical Association Journal

CT scan: computed tomography scan

ENT: ear, nose and throat

ITT: intention-to-treat

MPID: mean pain intensity difference

$\mathrm{N}$ : number

NSAID: non-steroidal anti-inflammatory drug

PRID: pain relief intensity difference

Tx: treatment

VAS: visual analogue scale 
Characteristics of excluded studies [ordered by study ID]

\begin{tabular}{ll}
\hline Study & Reason for exclusion \\
\hline Ozturk 2011 & Chronic sinusitis \\
\hline Remer 2005 & Chronic sinusitis \\
\hline Vaidyanathan 2011 & Chronic sinusitis with nasal polyposis \\
\hline
\end{tabular}


DATA AND ANALYSES

Comparison 1. Oral corticosteroids versus placebo or NSAID

\begin{tabular}{|c|c|c|c|c|}
\hline Outcome or subgroup title & $\begin{array}{l}\text { No. of } \\
\text { studies }\end{array}$ & $\begin{array}{c}\text { No. of } \\
\text { participants }\end{array}$ & Statistical method & Effect size \\
\hline $\begin{array}{l}1 \text { Proportion of patients with } \\
\text { resolution or improved } \\
\text { symptoms at days } 3 \text { to } 7\end{array}$ & 5 & 1043 & Risk Ratio (M-H, Random, 95\% CI) & $1.33[1.09,1.62]$ \\
\hline $\begin{array}{l}\text { 1.1 Co-treatment with } \\
\text { antibiotics }\end{array}$ & 4 & 869 & Risk Ratio (M-H, Random, 95\% CI) & $1.40[1.08,1.81]$ \\
\hline $\begin{array}{l}1.2 \text { Corticosteroid } \\
\text { monotherapy }\end{array}$ & 1 & 174 & Risk Ratio (M-H, Random, 95\% CI) & $1.12[0.87,1.44]$ \\
\hline $\begin{array}{l}2 \text { Proportion of patients with } \\
\text { resolution or improved } \\
\text { symptoms at days } 4 \text { to } 14\end{array}$ & 5 & 1116 & Risk Ratio (M-H, Random, 95\% CI) & $1.23[1.02,1.49]$ \\
\hline $\begin{array}{l}2.1 \text { Co-treatment with } \\
\text { antibiotics }\end{array}$ & 4 & 945 & Risk Ratio (M-H, Random, 95\% CI) & $1.32[1.04,1.68]$ \\
\hline $\begin{array}{l}2.2 \text { Corticosteroid } \\
\text { monotherapy }\end{array}$ & 1 & 171 & Risk Ratio (M-H, Random, 95\% CI) & $0.99[0.85,1.16]$ \\
\hline
\end{tabular}

Comparison 2. Sensitivity analysis - oral corticosteroids versus placebo

\begin{tabular}{lcccc} 
Outcome or subgroup title & $\begin{array}{c}\text { No. of } \\
\text { studies }\end{array}$ & $\begin{array}{c}\text { No. of } \\
\text { participants }\end{array}$ & Statistical method & Effect size \\
\hline $\begin{array}{l}1 \text { Proportion of patients with } \\
\text { resolution or improved } \\
\text { symptoms at days 3 to 7 }\end{array}$ & 4 & 840 & Risk Ratio (M-H, Fixed, 95\% CI) & $1.19[1.07,1.31]$ \\
$\begin{array}{c}2 \text { Proportion of patients with } \\
\text { resolution or improved } \\
\text { symptoms at days 4 to 14 }\end{array}$ & 4 & 913 & Risk Ratio (M-H, Fixed, 95\% CI) & $1.11[1.03,1.19]$ \\
\hline
\end{tabular}

Comparison 3. Best and worst-case scenario - oral corticosteroids versus NSAID or placebo

\begin{tabular}{|c|c|c|c|c|}
\hline Outcome or subgroup title & $\begin{array}{l}\text { No. of } \\
\text { studies }\end{array}$ & $\begin{array}{c}\text { No. of } \\
\text { participants }\end{array}$ & Statistical method & Effect size \\
\hline $\begin{array}{l}1 \text { Proportion of patients with } \\
\text { resolution or improved } \\
\text { symptoms at days } 3 \text { to } 7 \text { - } \\
\text { best-case scenario }\end{array}$ & 5 & 1193 & Risk Ratio (M-H, Random, 95\% CI) & $1.62[1.18,2.23]$ \\
\hline
\end{tabular}




\begin{tabular}{|c|c|c|c|c|}
\hline $\begin{array}{l}2 \text { Proportion of patients with } \\
\text { resolution or improved } \\
\text { symptoms at days } 3 \text { to } 7 \text { - } \\
\text { worst-case scenario }\end{array}$ & 5 & 1193 & Risk Ratio (M-H, Random, 95\% CI) & $1.07[0.77,1.48]$ \\
\hline $\begin{array}{l}3 \text { Proportion of patients with } \\
\text { resolution or improved } \\
\text { symptoms at days } 4 \text { to } 14 \text { - } \\
\text { best-case scenario }\end{array}$ & 5 & 1193 & Risk Ratio (M-H, Random, 95\% CI) & $1.33[1.11,1.61]$ \\
\hline $\begin{array}{l}4 \text { Proportion of patients with } \\
\text { resolution or improved } \\
\text { symptoms at days } 4 \text { to } 14 \text { - } \\
\text { worst-case scenario }\end{array}$ & 5 & 1193 & Risk Ratio (M-H, Random, 95\% CI) & $1.11[0.92,1.35]$ \\
\hline
\end{tabular}

Comparison 4. Best and worst-case scenario - oral corticosteroids versus placebo

\begin{tabular}{|c|c|c|c|c|}
\hline Outcome or subgroup title & $\begin{array}{l}\text { No. of } \\
\text { studies }\end{array}$ & $\begin{array}{c}\text { No. of } \\
\text { participants }\end{array}$ & Statistical method & Effect size \\
\hline $\begin{array}{l}1 \text { Proportion of patients with } \\
\text { resolution or improved } \\
\text { symptoms at days } 3 \text { to } 7 \text { - } \\
\text { best-case scenario }\end{array}$ & 4 & 974 & Risk Ratio (M-H, Random, 95\% CI) & $1.50[1.07,2.11]$ \\
\hline $\begin{array}{l}2 \text { Proportion of patients with } \\
\text { resolution or improved } \\
\text { symptoms at days } 3 \text { to } 7 \text { - } \\
\text { worst-case scenario }\end{array}$ & 4 & 974 & Risk Ratio (M-H, Random, 95\% CI) & $0.96[0.68,1.35]$ \\
\hline $\begin{array}{l}3 \text { Proportion of patients with } \\
\text { resolution or improved } \\
\text { symptoms at days } 4 \text { to } 14 \text { - } \\
\text { best-case scenario }\end{array}$ & 4 & 974 & Risk Ratio (M-H, Random, 95\% CI) & $1.18[1.10,1.27]$ \\
\hline $\begin{array}{l}4 \text { Proportion of patients with } \\
\text { resolution or improved } \\
\text { symptoms at days } 4 \text { to } 14 \text { - } \\
\text { worst-case scenario }\end{array}$ & 4 & 974 & Risk Ratio (M-H, Random, 95\% CI) & $1.00[0.87,1.14]$ \\
\hline
\end{tabular}


Analysis I.I. Comparison I Oral corticosteroids versus placebo or NSAID, Outcome I Proportion of patients with resolution or improved symptoms at days 3 to 7 .

Review: Systemic corticosteroids for acute sinusitis

Comparison: I Oral corticosteroids versus placebo or NSAID

Outcome: I Proportion of patients with resolution or improved symptoms at days 3 to 7

\begin{tabular}{|c|c|c|c|c|c|}
\hline Study or subgroup & $\begin{array}{r}\text { Oral corticosteroid } \\
n / N\end{array}$ & $\begin{array}{r}\text { Placebo or NSAID } \\
n / N\end{array}$ & $\begin{array}{r}\text { Risk Ratio } \\
\text { M- } \\
\text { H,Random,95\% } \\
\text { Cl }\end{array}$ & Weight & $\begin{array}{c}\text { Risk Ratio } \\
\text { M- } \\
\text { H,Random,95\% } \\
\text { Cl }\end{array}$ \\
\hline
\end{tabular}

I Co-treatment with antibiotics

Cannoni 1990

$79 / 103$

$40 / 100$

Gehanno 2000

158/208

$40 / 100$

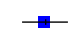

$20.4 \%$

$1.92[1.47,2.49]$

Klossek 2004

$60 / 103$

136/209

Ratau 2004

|5/21

$49 / 104$

Subtotal (95\% CI)

435

$10 / 21$

Total events: 312 (Oral corticosteroid), 235 (Placebo or NSAID)

434

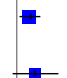

$28.1 \%$

$1.17[1.03,1.32]$

$20.5 \%$

$1.24[0.95,1.61]$

$9.9 \%$

$1.50[0.89,2.53]$

Heterogeneity: $\operatorname{Tau}^{2}=0.05 ; \mathrm{Chi}^{2}=12.03, \mathrm{df}=3(\mathrm{P}=0.0 \mathrm{I}) ; \mathrm{I}^{2}=75 \%$

Test for overall effect: $Z=2.57(P=0.010)$

2 Corticosteroid monotherapy

Venekamp 2012a

$55 / 88$

$48 / 86$

88

86

Subtotal (95\% CI)

ebo or NSAID)

Total events: 55 (Oral corticoste

Test for overall effect: $Z=0.89(P=0.37)$

Total (95\% CI)

523

520

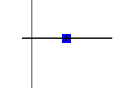

$78.8 \%$

$1.40[1.08,1.81]$

Total events: 367 (Oral corticosteroid), 283 (Placebo or NSAID)

Heterogeneity: $\mathrm{Tau}^{2}=0.03 ; \mathrm{Chi}^{2}=12.87, \mathrm{df}=4(\mathrm{P}=0.0 \mathrm{I}) ; \mathrm{I}^{2}=69 \%$

Test for overall effect: $Z=2.79(P=0.0052)$

Test for subgroup differences: $\mathrm{Chi}^{2}=1.50, \mathrm{df}=\mathrm{I}(\mathrm{P}=0.22), \mathrm{I}^{2}=33 \%$

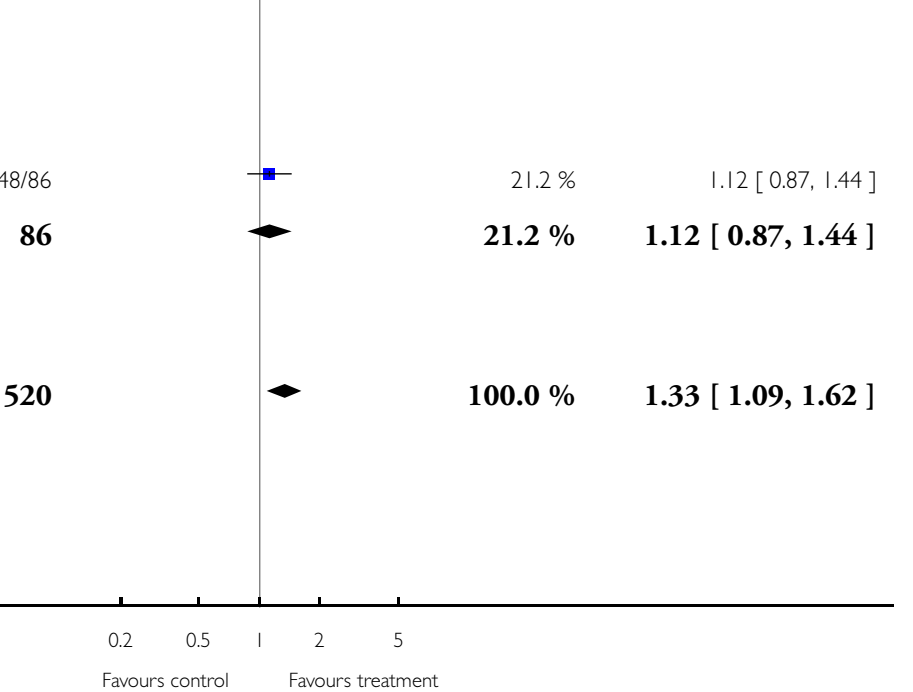


Analysis 1.2. Comparison I Oral corticosteroids versus placebo or NSAID, Outcome 2 Proportion of patients with resolution or improved symptoms at days 4 to I4.

Review: Systemic corticosteroids for acute sinusitis

Comparison: I Oral corticosteroids versus placebo or NSAID

Outcome: 2 Proportion of patients with resolution or improved symptoms at days 4 to 14

\begin{tabular}{|c|c|c|c|c|c|}
\hline Study or subgroup & Oral corticosteroid & Placebo or NSAID & $\begin{array}{c}\text { Risk Ratio } \\
\text { M- } \\
\text { H,Random,95\% } \\
\mathrm{Cl}\end{array}$ & Weight & $\begin{array}{c}\text { Risk Ratio } \\
\text { M- } \\
\text { H,Random,95\% }\end{array}$ \\
\hline
\end{tabular}

I Co-treatment with antibiotics

Cannoni 1990

$79 / 103$

$40 / 100$

$40 / 100$

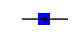

$18.0 \%$

$1.92[1.47,2.49]$

Gehanno 2000

158/208

Klossek 2004

$116 / 138$

136/209

| $14 / 145$

Ratau 2004

$10 / 21$

470

475

Subtotal (95\% CI)

Total events: 368 (Oral corticosteroid), 300 (Placebo or NSAID)
Heterogeneity: $\mathrm{Tau}^{2}=0.04 ; \mathrm{Chi}^{2}=18.98, \mathrm{df}=3(\mathrm{P}=0.00028) ;\left.\right|^{2}=84 \%$

Test for overall effect: $Z=2.29(P=0.022)$

2 Corticosteroid monotherapy

Venekamp 2012a

$69 / 87$

$67 / 84$

87

84
-

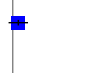

$24.6 \%$

$25.1 \%$

$8.9 \%$

$76.6 \%$

Total events: 69 (Oral corticosteroid), 67 (Placebo or NSAID)

Heterogeneity: not applicable

Test for overall effect: $Z=0.07(P=0.94)$

Total (95\% CI)

557

559

Total events: 437 (Oral corticosteroid), 367 (Placebo or NSAID)

Heterogeneity: $\operatorname{Tau}^{2}=0.03 ; \mathrm{Chi}^{2}=22.92, \mathrm{df}=4(\mathrm{P}=0.000 \mathrm{I} 3) ; \mathrm{I}^{2}=83 \%$

Test for overall effect: $Z=2.13(P=0.033)$

Test for subgroup differences: $\mathrm{Chi}^{2}=3.89, \mathrm{df}=\mathrm{I}(\mathrm{P}=0.05), \mathrm{I}^{2}=74 \%$
$23.4 \%$

$23.4 \%$

$67 / 84$

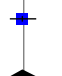

$0.99[0.85,1.16]$

0.99 [ $0.85,1.16$ ]

$100.0 \%$

$1.23[1.02,1.49]$ 
Analysis 2.I. Comparison 2 Sensitivity analysis - oral corticosteroids versus placebo, Outcome I Proportion of patients with resolution or improved symptoms at days 3 to 7 .

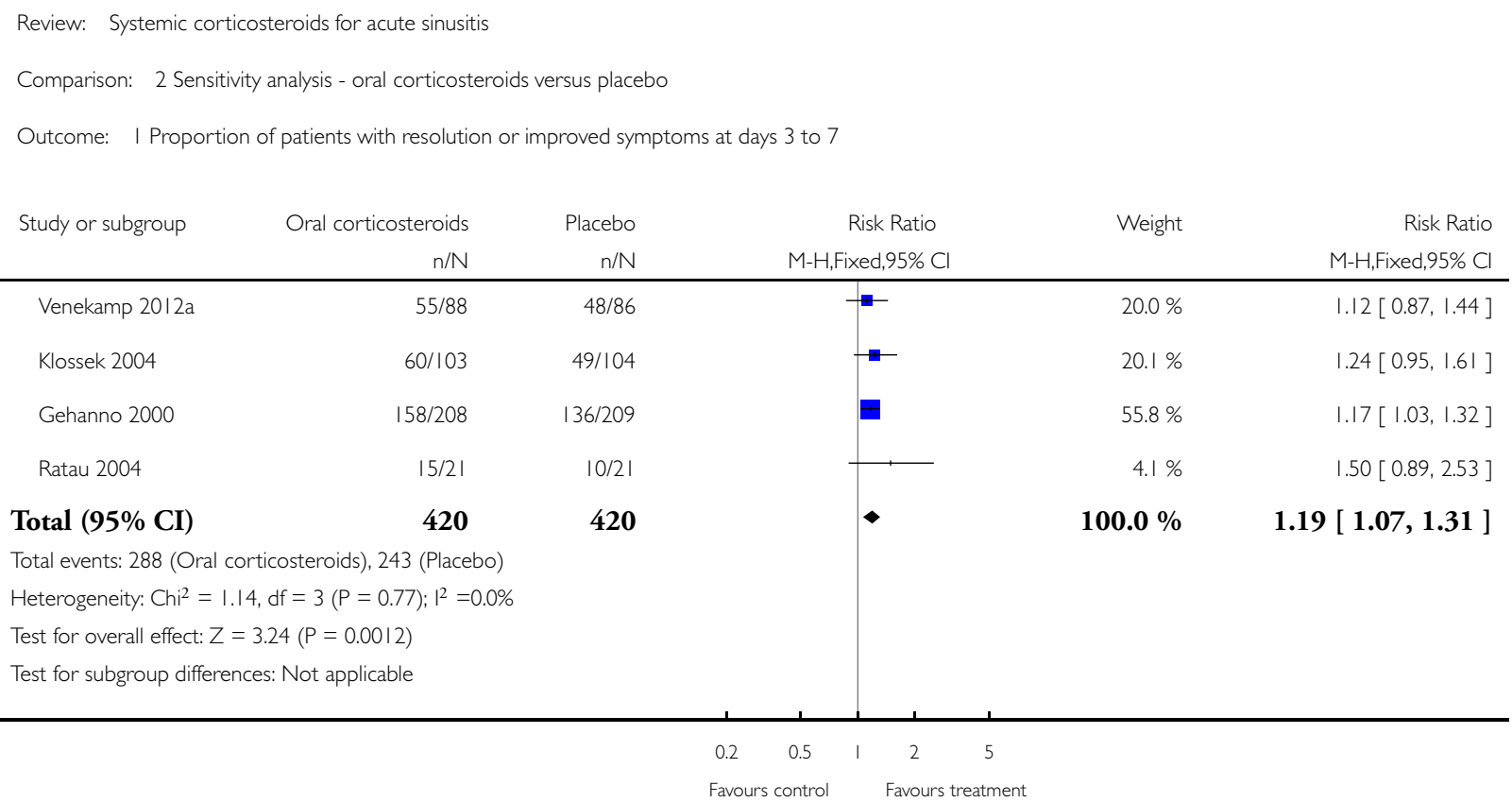


Analysis 2.2. Comparison 2 Sensitivity analysis - oral corticosteroids versus placebo, Outcome 2 Proportion of patients with resolution or improved symptoms at days 4 to I4.

Review: Systemic corticosteroids for acute sinusitis

Comparison: 2 Sensitivity analysis - oral corticosteroids versus placebo

Outcome: 2 Proportion of patients with resolution or improved symptoms at days 4 to 14

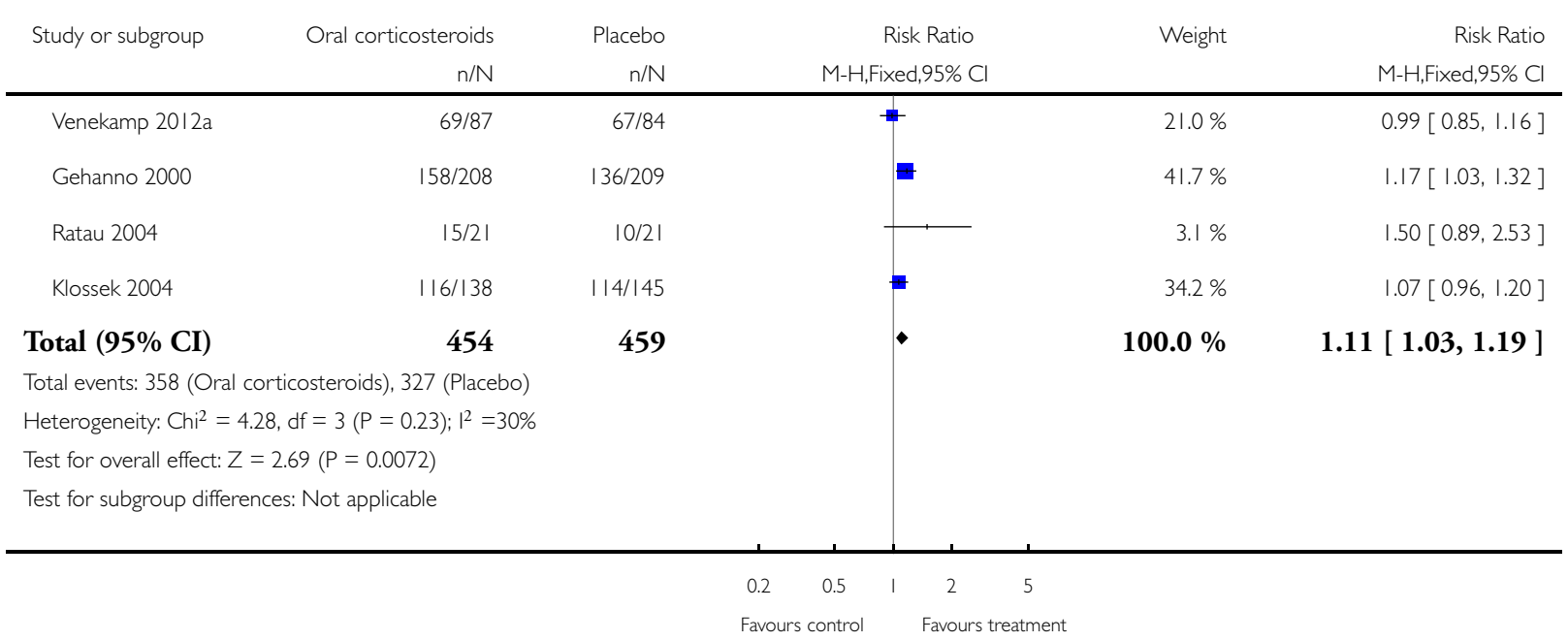


Analysis 3.I. Comparison 3 Best and worst-case scenario - oral corticosteroids versus NSAID or placebo, Outcome I Proportion of patients with resolution or improved symptoms at days 3 to 7 - best-case scenario.

Review: Systemic corticosteroids for acute sinusitis

Comparison: 3 Best and worst-case scenario - oral corticosteroids versus NSAID or placebo

Outcome: I Proportion of patients with resolution or improved symptoms at days 3 to 7 - best-case scenario

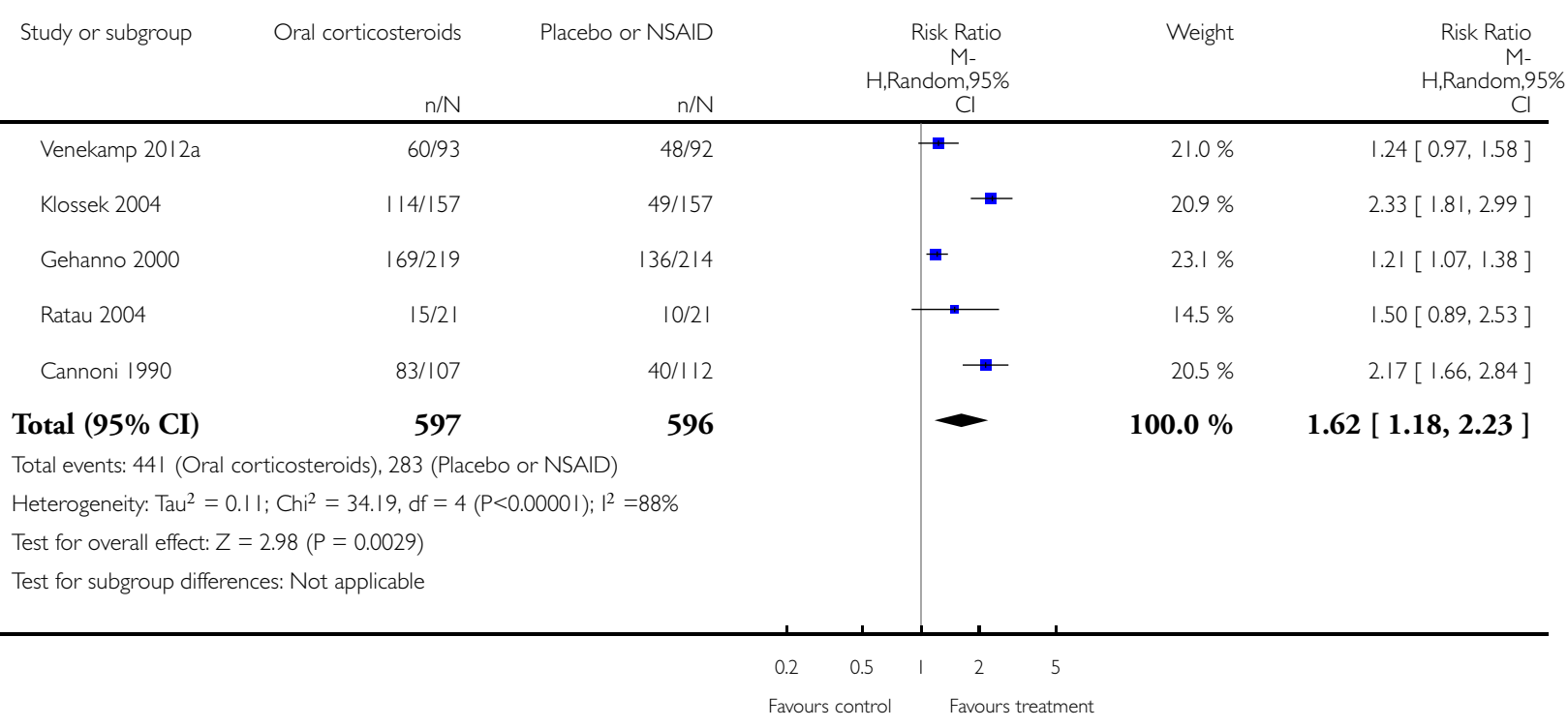


Analysis 3.2. Comparison 3 Best and worst-case scenario - oral corticosteroids versus NSAID or placebo, Outcome 2 Proportion of patients with resolution or improved symptoms at days 3 to 7 - worst-case scenario.

Review: Systemic corticosteroids for acute sinusitis

Comparison: 3 Best and worst-case scenario - oral corticosteroids versus NSAID or placebo

Outcome: 2 Proportion of patients with resolution or improved symptoms at days 3 to 7 - worst-case scenario

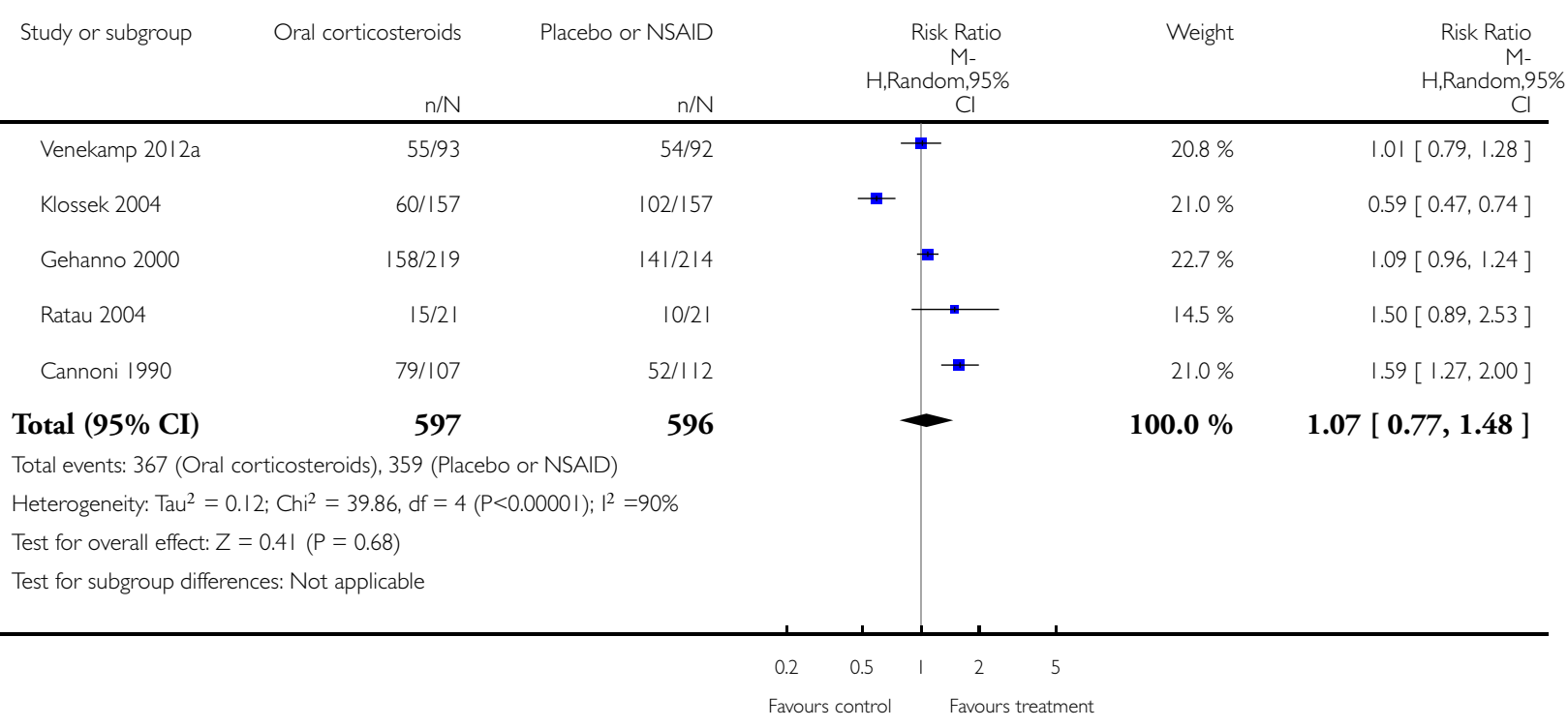


Analysis 3.3. Comparison 3 Best and worst-case scenario - oral corticosteroids versus NSAID or placebo, Outcome 3 Proportion of patients with resolution or improved symptoms at days 4 to I4 - best-case scenario.

Review: Systemic corticosteroids for acute sinusitis

Comparison: 3 Best and worst-case scenario - oral corticosteroids versus NSAID or placebo

Outcome: 3 Proportion of patients with resolution or improved symptoms at days 4 to 14 - best-case scenario

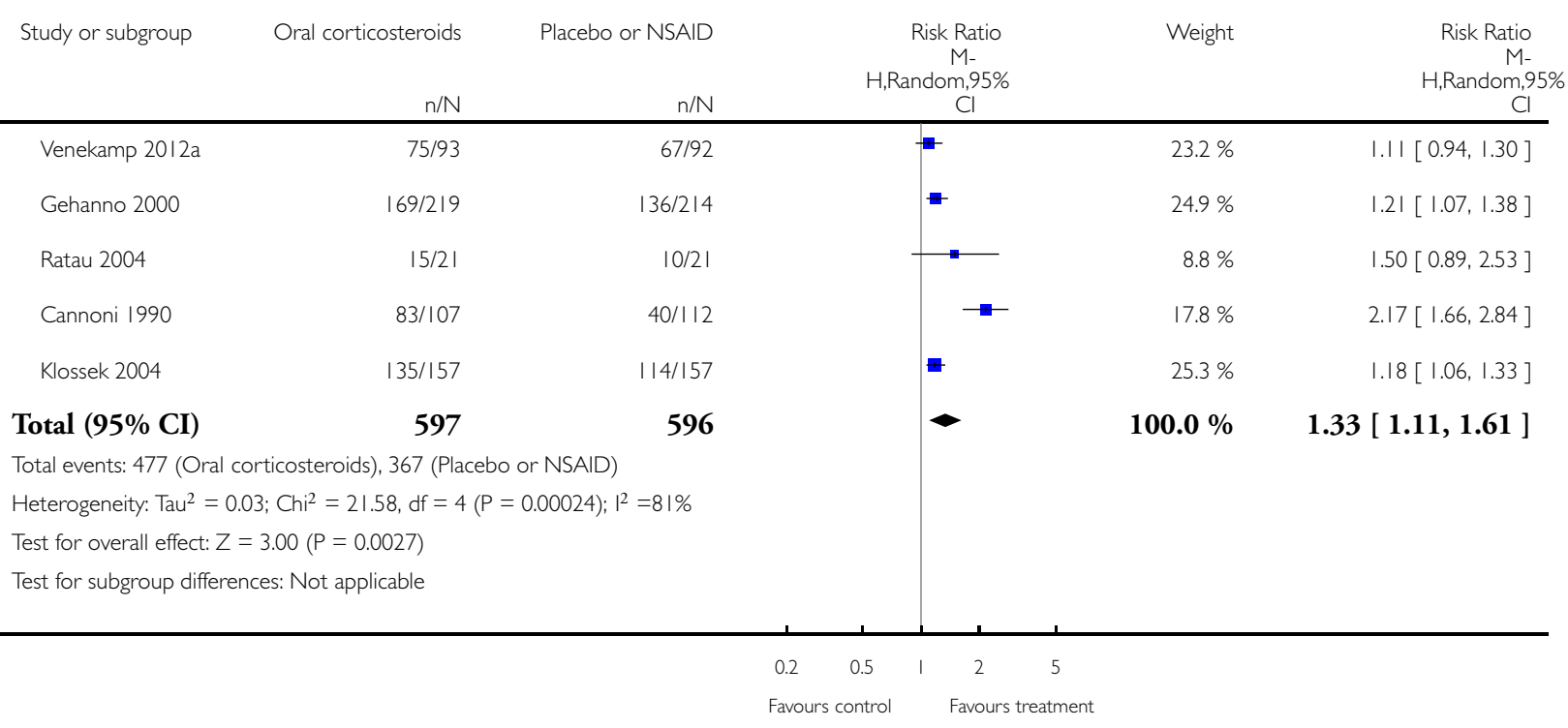


Analysis 3.4. Comparison 3 Best and worst-case scenario - oral corticosteroids versus NSAID or placebo, Outcome 4 Proportion of patients with resolution or improved symptoms at days 4 to 14 - worst-case scenario.

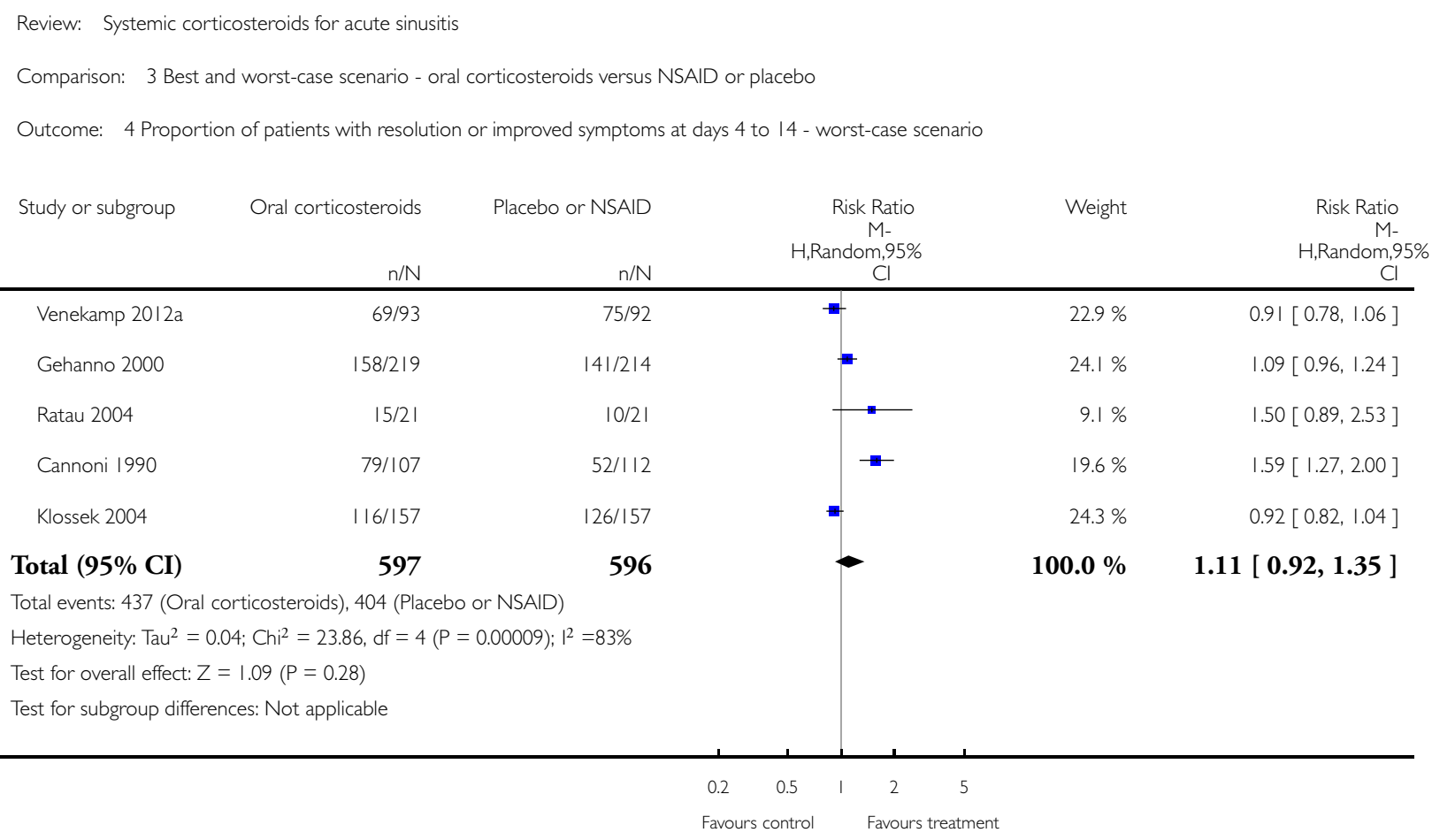


Analysis 4.I. Comparison 4 Best and worst-case scenario - oral corticosteroids versus placebo, Outcome I Proportion of patients with resolution or improved symptoms at days 3 to 7 - best-case scenario.

Review: Systemic corticosteroids for acute sinusitis

Comparison: 4 Best and worst-case scenario - oral corticosteroids versus placebo

Outcome: I Proportion of patients with resolution or improved symptoms at days 3 to 7 - best-case scenario

Study or subgroup $\quad$ Oral corticosteroids Placebo Risk Ratio $\quad$ Weight

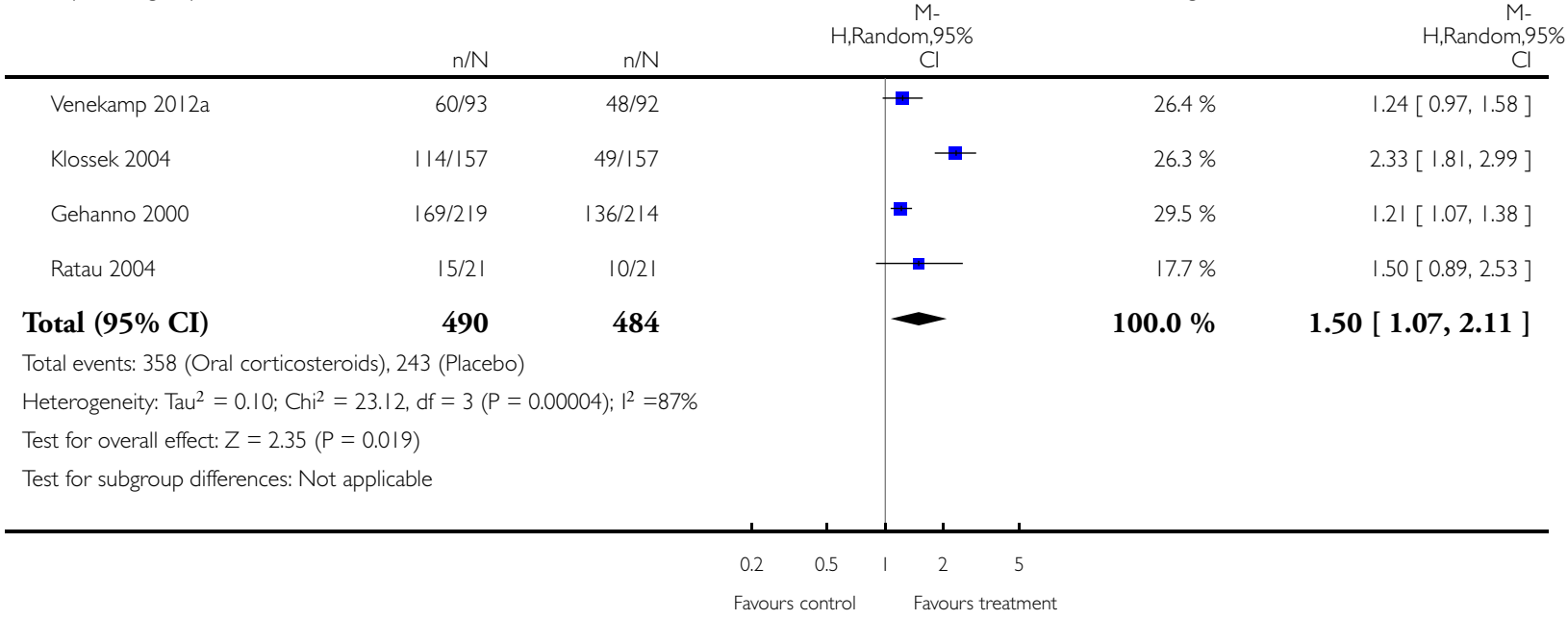


Analysis 4.2. Comparison 4 Best and worst-case scenario - oral corticosteroids versus placebo, Outcome 2 Proportion of patients with resolution or improved symptoms at days 3 to 7 - worst-case scenario.

Review: Systemic corticosteroids for acute sinusitis

Comparison: 4 Best and worst-case scenario - oral corticosteroids versus placebo

Outcome: 2 Proportion of patients with resolution or improved symptoms at days 3 to 7 - worst-case scenario

$\begin{array}{cc}\text { M- } & \text { M- } \\ \text { H, Random, } 95 \% & H, \text { Random, } 95 \%\end{array}$

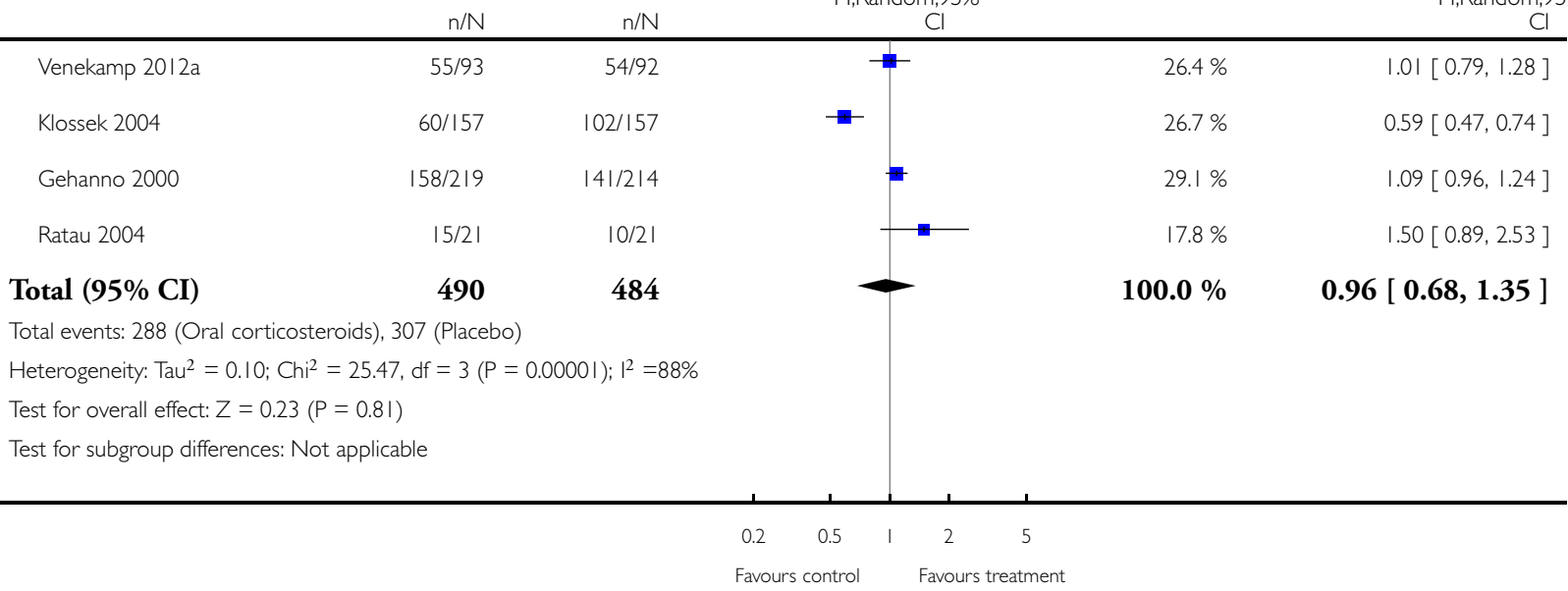


Analysis 4.3. Comparison 4 Best and worst-case scenario - oral corticosteroids versus placebo, Outcome 3 Proportion of patients with resolution or improved symptoms at days 4 to 14 - best-case scenario.

Review: Systemic corticosteroids for acute sinusitis

Comparison: 4 Best and worst-case scenario - oral corticosteroids versus placebo

Outcome: 3 Proportion of patients with resolution or improved symptoms at days 4 to 14 - best-case scenario

Study or subgroup Oral corticosteroids Placebo Risk Ratio Ris Ratio H,Random. $95 \%$ H.

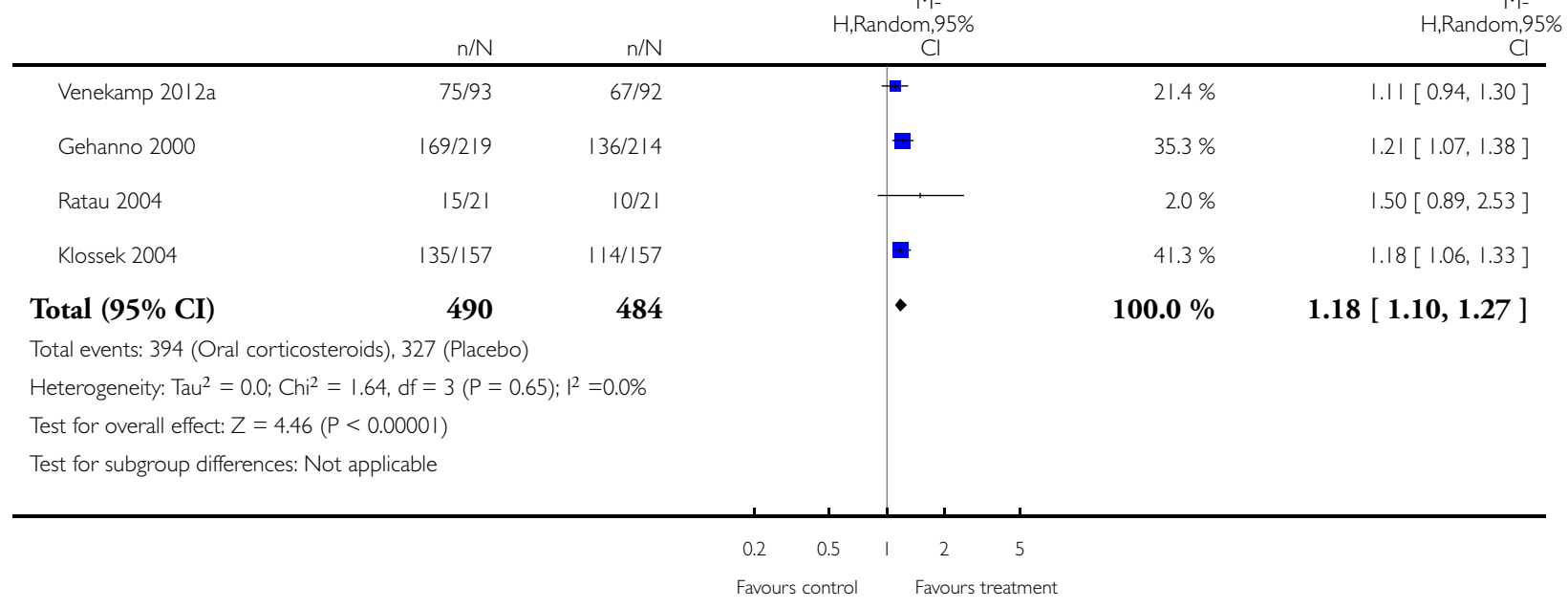




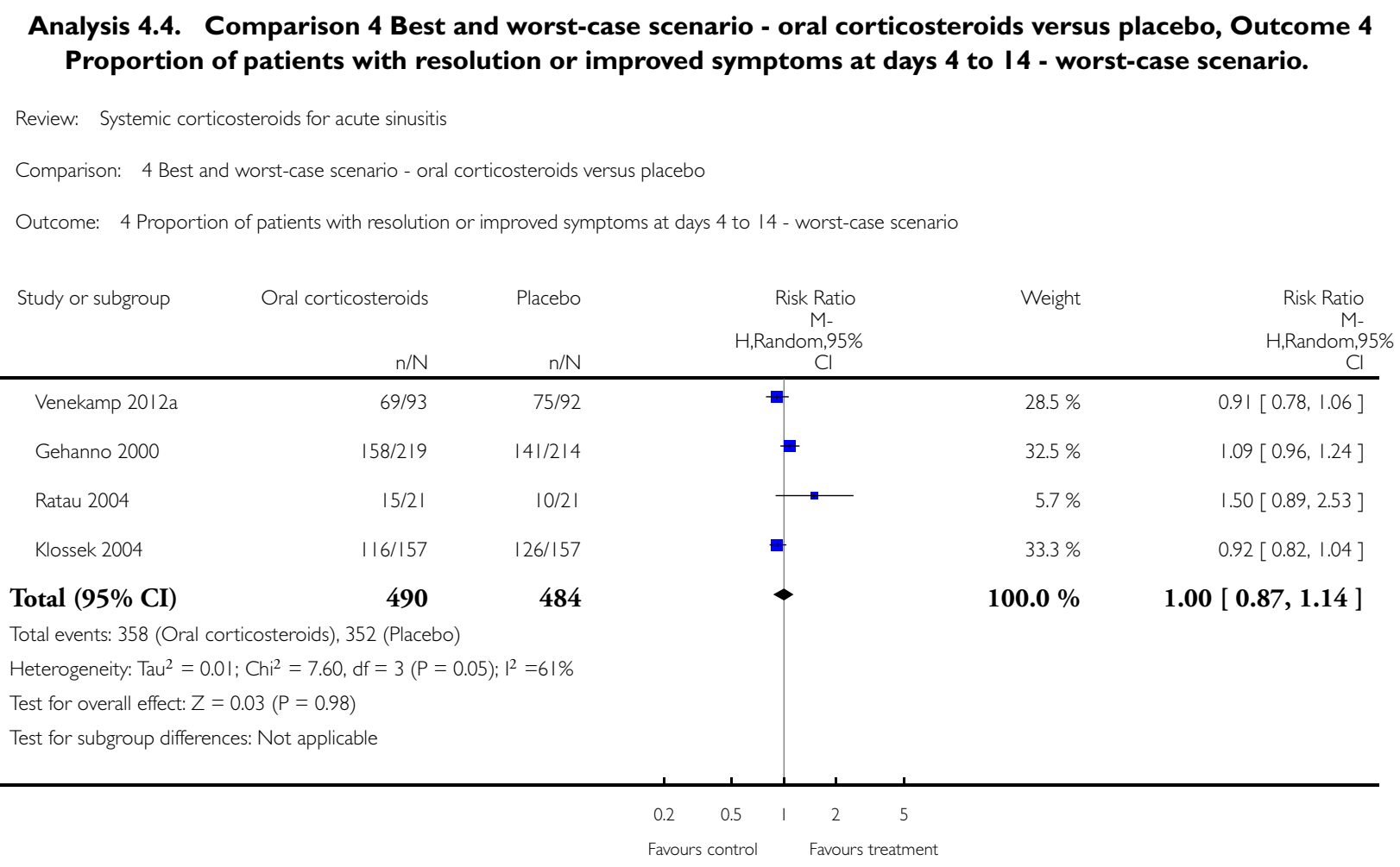

\section{ADDITIONAL TABLES}

Table 1. Adverse events

\begin{tabular}{|c|c|c|c|c|}
\hline Study & Intervention & Comparison & Side effects & Comments \\
\hline Cannoni 1990 & $\begin{array}{l}\text { Prednisolone } 40 \mathrm{mg} \text { once } \\
\text { daily for participants with } \\
\text { a weight }<60 \mathrm{~kg} \text { and } \\
\text { prednisolone } 60 \mathrm{mg} \text { once } \\
\text { daily for participants with } \\
\text { a weight }>60 \mathrm{~kg} \text { for } 7 \text { days }\end{array}$ & $\begin{array}{l}\text { Niflumic acid (NSAID) } \\
250 \mathrm{mg} 3 \text { daily for } 7 \text { days }\end{array}$ & $\begin{array}{l}\text { Nausea, vomiting, gastric } \\
\text { complaints }\end{array}$ & $\begin{array}{l}\text { Adverse events } \\
\text { NSAID group versus cor- } \\
\text { ticosteroid group: } 51 \text { ver- } \\
\text { sus } 23(\mathrm{P}<0.05) \\
\text { Discontin- } \\
\text { uation of study participa- } \\
\text { tion due to adverse events } \\
\text { NSAID group versus cor- } \\
\text { ticosteroid group: } 7 \text { versus } \\
0(\mathrm{P}<0.05)\end{array}$ \\
\hline Gehanno 2000 & $\begin{array}{l}\text { Methylprednisolone } 8 \mathrm{mg} \\
3 \text { daily for } 5 \text { days }\end{array}$ & Placebo & $\begin{array}{l}\text { Nausea, vomiting, diar- } \\
\text { rhoea, gastric pain, skin re- } \\
\text { actions and candidal su- } \\
\text { perinfection }\end{array}$ & $\begin{array}{l}\text { Intercurrent events cor- } \\
\text { ticosteroid group versus } \\
\text { placebo group: } 24(11 \%) \\
\text { versus } 22(10 \%)\end{array}$ \\
\hline
\end{tabular}


Table 1. Adverse events (Continued)

Dis-

continuation of treatment due to intercurrent events corticosteroid group versus placebo group: 5 versus 3

\begin{tabular}{|c|c|}
\hline Klossek 2004 & $\begin{array}{l}\text { Prednisone } 0.8 \text { to } 1.2 \mathrm{mg} / \\
\mathrm{kg} \text { (weight } 40 \text { to } 60 \mathrm{~kg}: 40 \\
\mathrm{mg} \text {, weight } 60 \text { to } 80 \mathrm{~kg} \text { : } \\
60 \mathrm{mg} \text {, weight }>80 \mathrm{~kg}: 80 \\
\mathrm{mg} \text { ) for } 3 \text { days }\end{array}$ \\
\hline
\end{tabular}

Vomiting, diarrhoea abdominal pain, allergic reaction
46 adverse events were noted; no statistical difference between the groups $7 / 46$ were rated as severe by the patient: 3 in corticosteroid group (1 diarrhoea, 1 acute gastroenteritis, 1 abdominal pain) versus 4 in placebo group (1 vomiting, 1 abdominal pain, 1 neuralgia, 1 ear pain)

5 adverse events are possibly related to the treatment: 4 in corticosteroid group (diarrhoea, acute gastroenteritis, abdominal pain, allergic reaction) and 1 in placebo group (moderate colitis)

\begin{tabular}{l|l|l|} 
Ratau 2004 & $\begin{array}{l}\text { Betamethasone } 1 \text { Placebo } \\
\text { mg orally once daily for } 5\end{array}$ & \\
days
\end{tabular}
ported

tions of new diseases as-
No adverse events re- No adverse events or erupsociated with the use of betamethasone were reported

2 adverse reactions were reported in the placebo group: cough and maculopapular rash \begin{tabular}{l|l|l} 
Venekamp 2012a & $\begin{array}{l}\text { Prednisolone } 30 \mathrm{mg} \text { orally } \\
\text { once daily for } 7 \text { days }\end{array}$ & Placebo
\end{tabular}
Gastric complaints, diar- No statistically significant rhoea, increased appetite, differences were observed mood disturbance, sleep between groups at either 1 disturbance or 2 weeks

In total, 2 serious adverse events not related to drug use were reported: 1 hospital admission for anaemia on day 49 of the study in the placebo group and 1 hospital admission for 
Table 1. Adverse events (Continued)

wasp sting-induced anaphylaxis on day 28 of the study in the prednisolone group

NSAID: non-steroidal anti-inflammatory drug

\section{A P P E N D I CES}

\section{Appendix I. MEDLINE (Ovid) and CENTRAL search strategy}

1 exp Sinusitis/

2 sinusit*.tw.

3 (rhinosinusit* or nasosinusit*).tw.

4 ((sinus* or paranasal or para-nasal or nasopharynx or naso-pharynx) adj3 (infect* or inflam*)).tw.

5 purulent nasal discharge*.tw.

6 (nasal adj3 obstruct*).tw.

7 Rhinitis/

8 rhinit*.tw.

9 or/1-8

10 Adrenal Cortex Hormones/

11 corticosteroid*.tw,nm.

12 exp Glucocorticoids/

13 exp Hydroxycorticosteroids/

14 exp Pregnenediones/

15 hydrocortisone.tw,nm.

16 hydroxypregnenolone.tw,nm.

17 pregnenolone.tw,nm.

18 tetrahydrocortisol.tw, nm.

19 cortodoxone.tw,nm.

20 cortisone.tw, nm.

21 corticosterone.tw, nm.

22 hydroxycorticosteroid*.tw,nm.

23 glucocorticoid*.tw,nm.

24 triamcinolone.tw, nm.

25 prednisone.tw, nm.

26 prednisolone.tw,nm.

27 paramethasone.tw,nm.

28 methylprednisolone.tw,nm.

29 dexamethasone.tw,nm.

30 clobetasol.tw,nm.

31 beclomethasone.tw, nm

32 betamethasone.tw,nm.

33 budesonide.tw, nm.

34 steroid*.tw,nm. 
35 (efcortesol or hydrocortone or solu-cortef).tw,nm.

36 (betnelan or betnesol).tw,nm.

37 (deflazacort or calcort).tw,nm.

38 (medrone or solu-medrone or depo-medrone).tw,nm.

39 kenalog.tw,nm.

40 (novolizer or pulmicort or symbicort).tw,nm.

41 (beclometasone or aerobec or asmabec or beclazone or becodisks or becotide or clenil modulite or qvar or becloforte).tw.

42 or/ $10-41$

439 and 42

\section{Appendix 2. EMBASE.com search strategy}

47. \#43 AND \#46

46. \#44 OR \#45

45. random*:ab,ti OR placebo*:ab,ti OR factorial*:ab,ti OR crossover*:ab,ti OR 'cross over':ab,ti OR 'cross-over':ab,ti OR volunteer*: ab,ti OR allocat*:ab,ti OR assign*:ab,ti OR ((singl* OR doubl*) NEAR/2 (mask* OR blind*)):ab,ti

44. 'randomised controlled trial'/exp OR 'single blind procedure'/exp OR 'double blind procedure'/exp OR 'crossover procedure'/exp 43. \#10 AND \#42

42. \#11 OR \#12 OR \#13 OR \#14 OR \#15 OR \#16 OR \#17 OR \#18 OR \#19 OR \#20 OR \#21 OR \#22 OR \#23 OR \#24 OR \#25

OR \#26 OR \#27 OR \#28 OR \#29 OR \#30 OR\#31 OR\#32 OR \#33 OR \#34 OR \#35 OR \#36 OR \#37 OR \#38 OR \#39 OR \#40 OR \#41

41. aerobec:ab,ti OR asmabec:ab,ti OR beclazone:ab,ti OR becodisks:ab,ti OR becotide:ab,ti OR qvar:ab,ti OR becloforte:ab,ti OR 'clenil modulite':ab,ti

40. novolizer:ab,ti OR pulmicort:ab,ti OR symbicort:ab,ti

39. kenalog:ab,ti AND [embase]/lim

38. medrone:ab,ti OR 'solu medrone':ab,ti OR 'depo medrone':ab,ti

37. deflazacort:ab,ti OR calcort:ab,ti

36. betnelan:ab,ti OR betnesol:ab,ti

35. efcortesol:ab,ti OR hydrocortone:ab,ti OR 'solu cortef':ab,ti

34. steroid:ab,ti

33. budesonide: $\mathrm{ab}, \mathrm{ti}$

32. betamethasone:ab,ti

31. beclomethasone:ab,ti OR beclometasone:ab,ti

30. clobetasol:ab,ti

29. dexamethasone:ab,ti

28. methylprednisolone:ab,ti

27. paramethasone:ab,ti

26. prednisolone:ab,ti

25. prednisone:ab,ti

24. triamcinolone: $\mathrm{ab}, \mathrm{ti}$

23. glucocorticoid*:ab,ti

22. hydroxycorticosteroid*:ab,ti

21. corticosterone:ab,ti

20. cortisone:ab,ti

19. cortodoxone:ab,ti

18. tetrahydrocortisol:ab,ti

17. pregnenolone:ab,ti

16. hydroxypregnenolone:ab,ti

15. hydrocortisone:ab,ti

14. pregnenedione*:ab,ti

13. 'glucocorticoid'/exp OR 'hydroxycorticosteroid'/de OR 'pregnane derivative'/de

12. corticosteroid*:ab,ti

Systemic corticosteroids for acute sinusitis (Review)

Copyright $(2014$ The Cochrane Collaboration. Published by John Wiley \& Sons, Ltd. 
11. 'corticosteroid'/de

10. \#1 OR \#2 OR \#3 OR \#4 OR \#5 OR \#6 OR \#7 OR \#8 OR \#9

9. rhinit*:ab,ti

8. 'rhinitis'/de

7. (nasal NEAR/3 obstruct*):ab,ti

6. 'purulent nasal discharge':ab,ti

5. ((sinus* OR paranasal OR 'para nasal' OR nasopharynx OR 'naso pharynx') NEAR/3 (infect* OR inflam*)):ab,ti

4. rhinosinusit*:ab,ti OR nasosinusit*:ab,ti

3. 'rhinosinusitis'/de

2. sinusit*:ab,ti

1. 'sinusitis'/exp

\section{WHAT'S NEW}

Last assessed as up-to-date: 19 February 2014.

\begin{tabular}{|c|c|c|}
\hline Date & Event & Description \\
\hline 19 February 2014 & $\begin{array}{l}\text { New citation required but conclusions have not } \\
\text { changed }\end{array}$ & $\begin{array}{l}\text { Oral corticosteroids as a monotherapy appear to be inef- } \\
\text { fective for adult patients with clinically diagnosed acute } \\
\text { sinusitis. Current data on the use of oral corticosteroids } \\
\text { as an adjunctive therapy to oral antibiotics are limited: } \\
\text { almost all trials are performed in secondary care and } \\
\text { there is a significant risk of bias. This limited evidence } \\
\text { suggests that oral corticosteroids in combination with } \\
\text { antibiotics may be modestly beneficial for short-term } \\
\text { relief of symptoms in acute sinusitis, with a number } \\
\text { needed to treat to benefit of seven for resolution or im- } \\
\text { provement of symptoms. A large primary care factorial } \\
\text { trial is needed to establish whether oral corticosteroids } \\
\text { offer additional benefits over antibiotics in acute sinusi- } \\
\text { tis }\end{array}$ \\
\hline
\end{tabular}

19 February 2014 New search has been performed

We updated the searches in February 2014. One new trial was identified (Venekamp 2012a). This study included adults with clinically diagnosed acute sinusitis in primary care and assessed the effectiveness of a short course of oral corticosteroids (prednisolone 30 $\mathrm{mg}$ /day for seven days) as a monotherapy compared to placebo. We judged the risk of bias to be low. This trial provided data on resolution of facial pain/pressure and other symptoms at day seven, day 14 and eight weeks, time lapse before resolution of symptoms and adverse events. Systemic corticosteroid monotherapy appeared to be ineffective for adult patients with clinically diagnosed acute sinusitis

We did not identify any ongoing trials. 


\section{CONTRIBUTIONSOFAUTHORS}

Gail Hayward drafted the protocol. The manuscript was reviewed by all of the review authors.

\section{DECLARATIONSOF INTEREST}

Roderick P. Venekamp and Maroeska M. Rovers were involved in the PRET (Prednisolone Rhinosinusitis Efficacy Trial) study entitled 'Optimal treatment of rhinosinusitis-like symptoms: double-blind placebo controlled randomised study with prednisolone versus usual care treatment' (Venekamp 2012a). This trial has been included in this 2014 update. To avoid any potential conflicts of interest, two other review authors (Gail Hayward, Paul Glasziou) performed 'Risk of bias' assessment and data extraction for this trial.

Maroeska M. Rovers has participated in a workshop and educational activities on otitis media organised by GlaxoSmithKline and received a grant from GlaxoSmithKline for a study on the microbiology of otitis media in 2009.

Paul Glasziou is an investigator on a five-year National Health and Medical Research Council (NHMRC) grant looking at antibiotic prescribing and resistance. He is on the board of Therapeutic Guidelines Ltd, which produces the Antibiotic Guidelines booklet.

Matthew J Thompson, Gail Hayward, Carl J Heneghan, Chris B Del Mar and Rafael Perera: none known.

\section{SOURCES OF SUPPORT}

\section{Internal sources}

- No sources of support supplied

\section{External sources}

- British Association of Antimicrobial Chemotherapy, UK.

Funding for this work was provided in part by a Systematic Review Grant (GA722SRG) from the British Society for Antimicrobial Chemotherapy

\section{INDEX TERMS}

\section{Medical Subject Headings (MeSH)}

Acute Disease; Administration, Oral; Adrenal Cortex Hormones [*therapeutic use]; Anti-Bacterial Agents [*therapeutic use]; AntiInflammatory Agents, Non-Steroidal [therapeutic use]; Betamethasone [therapeutic use]; Prednisone [therapeutic use]; Randomized Controlled Trials as Topic; Sinusitis [*drug therapy]

\section{MeSH check words}

Adolescent; Adult; Humans 